\title{
Railway ground vibration and mitigation measures: benchmarking of best practices
}

\author{
Slimane Ouakka ${ }^{1}$ (D) Olivier Verlinden $^{1}$ (i) $\cdot$ Georges Kouroussis $^{1}$ (i)
}

Received: 10 September 2021/Revised: 28 October 2021/Accepted: 3 November 2021/Published online: 8 January 2022 (C) The Author(s) 2022

\begin{abstract}
Vibration and noise aspects play a relevant role in the lifetime and comfort of urban areas and their residents. Among the different sources, the one coming from the rail transit system will play a central concern in the following years due to its sustainability. Ground-borne vibration and noise assessment as well as techniques to mitigate them become key elements of the environmental impact and the global enlargement planned for the railway industry. This paper aims to describe and compare the different mitigation systems existing and reported in literature through a comprehensive state of the art analysis providing the performance of each measure. First, an introduction to the ground-borne vibration and noise generated from the wheel-rail contact and its propagation through the transmission path is presented. Then, the impact and the different ways of evaluating and assessing these effects are presented, and the insertion loss indicator is introduced. Next, the different mitigation measures at different levels (vehicle, track, transmission path and receiver) are discussed by describing their possible application and their efficiency in terms of insertion loss. Finally, a summary with inputs of how it is possible to address the future of mitigation systems is reported.
\end{abstract}

Keywords Ground-borne noise and vibration - Railway dynamics · Urban railway · Vibration mitigation · Insertion loss $\cdot$ Vibration isolation

Georges Kouroussis

georges.kouroussis@umons.ac.be

1 Department of Theoretical Mechanics, Dynamics and Vibrations, Faculty of Engineering, University of Mons, Mons, Belgium

\section{Introduction}

In modern times, ground-borne vibration and noise exposure to the residents are higher than the ancient time, hence also their perception by people and all living beings. The ground-borne effects can be a serious concern for nearby neighbours of a transit system route such as rail and road traffic, or maintenance facility such as blasting, pile-driving and operating heavy earth-moving types of equipment $[1,2]$.

Among the possible sources, the one coming from the rail traffic is of significant importance, due to the roleplaying in the transportation of contemporary society. In addition, according to the European vision, this is also expected to increase in the coming years to be able to cover $50 \%$ of the total and transportation [3] since it is among the most sustainable means of transport that can be a feasible alternative to the oil-based transportation [4]. The expansion and development of railway lines inevitably lead the surrounding areas to be affected by the effects of the train passage, in the form of induced ground-borne vibration, ground-borne noise and air-borne noise [5] as depicted in Fig.1. These negative effects have been to a certain extent a limitation for the development of railways, especially in urban areas where significant levels of vibration to which residents in proximity to the lines are subjected [6].

Ground-borne vibration (which is the most commonly perceived sort of "vibration") is generated by the interaction between trains, track and subsoil. The vibration is then transmitted through the ground and may reach the foundation of a building. The building responds to the vibration of the foundations, and then the vibration is transmitted through the building structure and may be observed with the oscillation of floors and walls. Ground-borne vibration is associated with a frequency range of roughly between 1 


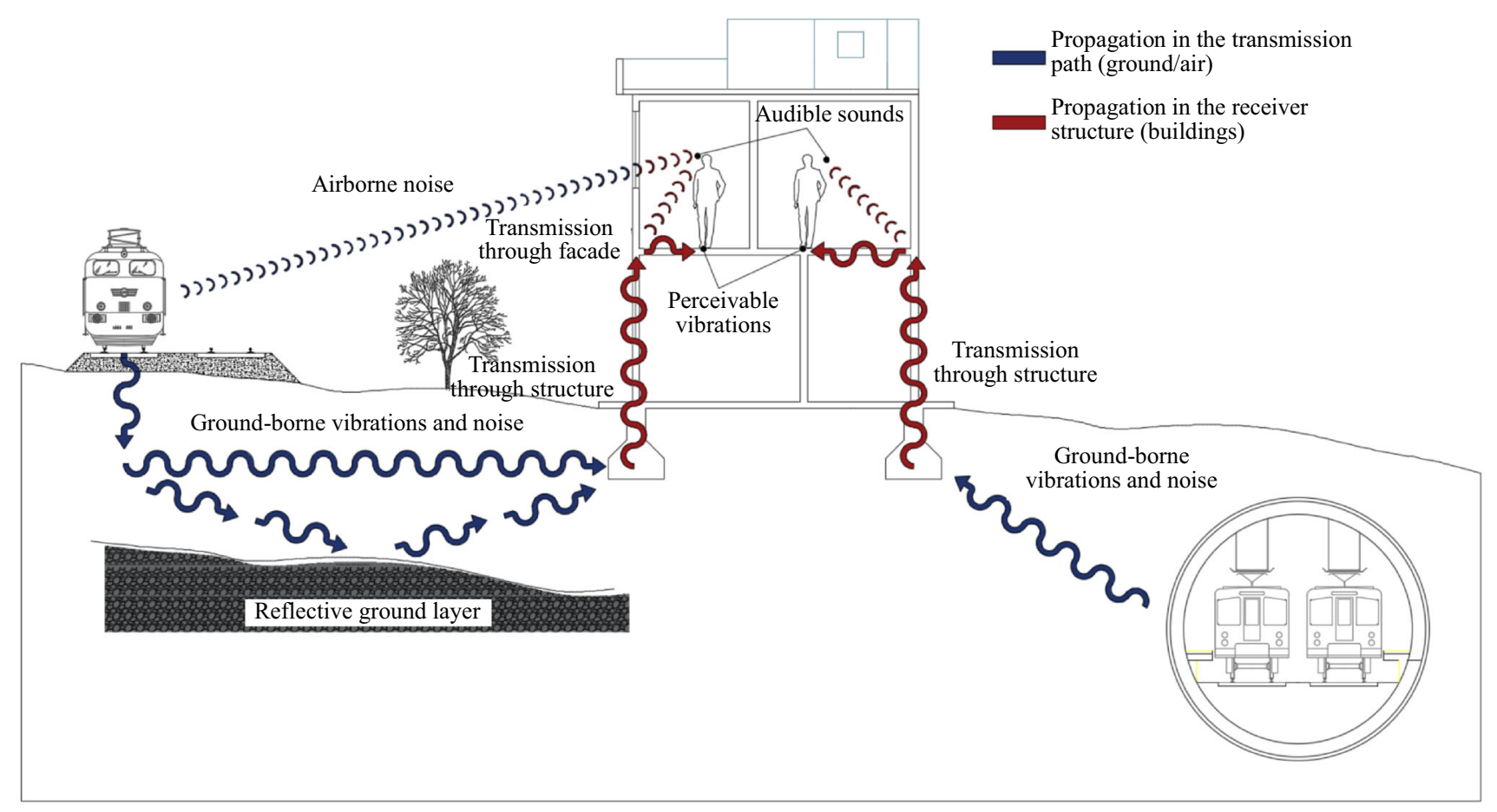

Fig. 1 Surface and underground railway mechanism effects and transmission paths of air-borne noise, ground-borne vibration and noise

and $100 \mathrm{~Hz}$ [7]. Correspondingly, it is defined by the ISO 14837-1 [8], as the "vibration generated from the pass-by of the vehicle on the rail, propagated through the ground or structure into a receiving building".

On the other hand, ground-borne railway noise is defined in ISO 14837-1 [8], as "noise generated inside a building by ground-borne vibration generated from the pass-by of a vehicle on rail". It includes both heavy and light rail transit as well as low and high-speed trains (HSTs). Notice that ground-borne noise is sometimes referred to as re-radiated noise, structure-borne noise [9] or solid-borne noise (according to ISO 14837); in this manuscript, it will refereed as ground-borne noise. Its frequency range is roughly between 20 and $250 \mathrm{~Hz}$ [7].

Air-borne railway noise is instead generated by the wheel-rail contact and the different train on-board equipment (e.g., traction, ventilation and air conditioning) $[10,11]$; the noise is radiated by the track and the surface train, then travels through the air toward the nearby buildings, where it is transmitted through the facades inside buildings as audible noise. In the propagation paths (air in this case), numerous phenomena are attenuating the noise, for instance, the distance between the source and the resident [12, 13] and the sound insulation of the facade [14]. Air-borne noise can be in the full audio range between 20 and 20,000 Hz. However, air-borne is beyond the intent of this research, which focuses on the other two effects that propagate through the ground i.e., ground-borne noise and vibration, presented above.

Both vibration and noise have been a subject of serious concern in public opinion due to the caused annoyance that influences the daily life of the exposed people (e.g., sleep, communication, etc.) $[15,16]$. Furthermore, the prospected amplification in the European and global railway grid, to meet the needs in the transportation of people and goods within the low carbon targets, will certainly convey to an increase in the number of trains which in turn will inevitably lead to an enhancement in the annoyance $[17,18]$.

Recent studies and investigations have highlighted in addition to the annoyance, some permanent effects on the health of the exposed people. For example, the investigation made in 2013 by Croy et al. [19] have demonstrated that in some circumstance the passage of trains provokes acceleration of the heart rate during sleep up to $3 \mathrm{bpm}$, and this in long term may affect cardiovascular functioning of persons living close to railways. Whereas, the interview study done by Maclachlan et al. in 2017 [20] have demonstrated that vibrations from rail transport for those living in proximity to the source, have negative repercussions for restoration all-day-long and that this exposure may have long-term health effects, as a result of disruption to the body's normal homeostatic stress response.

For better understanding of the ground-borne effects, different researches and investigations have been conducted in the last four decades. The International Union of 
Railways (UIC) gave recently a general overview of the state of the art in induced vibration [7]. Other research had a focus on the different parts involved in the railway environment like Kouroussis et al. [21, 22] and Ouakka et al. [23]. Whereas, further studies such as Smith et al. [24, 25], Öhrström [26] and Kouroussis et al. [27, 28] have put the emphasis on the consequences of the effects to nearby structure and the residents.

Due to the nature of the problem and its complexity, it is not straightforward to predict the propagation and the intensity of the ground-borne effects. The assessment of these effects will be discussed in detail later in this paper. However, it is obvious that the more accurate approach is to investigate the effects by direct measurements in the field $[29,30]$ or by reproducing the railway environment with laboratory tests (e.g., [31]). On the other hand, these two approaches have some drawbacks including time and budget cost, and in the case of field measurements, these are only applicable to existing grids (or to a physical prototype). The economic and valuable alternative to laboratory tests is the use of numerical simulations (aka virtual prototyping), as this has been demonstrated in railway [32-36], as well as in other different fields $[37,38]$.

With numerical simulations, it is possible to reproduce the railway environment and not only, but this can also be seen as a great point since the models needed to combine different elements from the source to the receiver and beyond these. A number of numerical models, based on finite element and boundary element approaches, have been developed by various research teams in an attempt to understand the propagation of railway induced vibration. Both in frequency domain [39-42] and time-domain [43-45] approaches have been considered. For example, the model developed by Kouroussis et al. [46, 47] represents a promising way to consider the whole vehicle/track/soil/receiver system by working in two steps in order to separate each subsystem and to easily evaluate the contribution of each subdomain.

Finally, the purpose of this document is dictated by the importance of having knowledge and strategies on how to reduce ground vibration effects coming from the rail passage, in order to be able to implement and develop them. Mitigation systems, of which this research gives a review, are of different nature and can be applied in all the interesting subsystems (i.e., vehicle, track and propagation path) and the affected entity (i.e., neighbouring buildings, equipment and people). Some preceding studies in how to mitigate the effects of the railway passage have been conducted in the last years [27, 48, 49]. However, due to the variety and complexity of the problem, there are many other ways for improvements. Therefore, this paper gives an overall overview considering also the recent advancement in the field, as discussed in the following sections.

\section{Ground-borne vibration and noise}

In this section, the characteristics and the effects of vibrations coming from wheel-rail contact will be presented. However, since the acceptable noise and vibration thresholds change from country to country, different standards and guidelines are available in the literature to define adequate procedures and assessments in the area where the rail line is operating. This is also because countries generally do not have a comprehensive regulation to mitigate the vibration coming from the railway, but they generally provide only guidelines and recommendations based on a range of standards, either international or regional:

- ISO 2631 [50, 51], which are often considered as a reference for comfort evaluation,

- EN 12299 [52], that defines and evaluates the train passenger comfort,

- ISO 4866 [53], for measurement and processing data with regard to evaluating vibration effects on structures;

or national standards:

- the British Standards BS 6841 [54] and BS 6472-1 [55] considered very similar to the aforementioned ISO standards,

- the German standards DIN 4150 [56, 57], used also in UK, Belgium and other European countries,

- the Swiss standards SN 640 312a [58] dealing with building damage only,

- the Norwegian standard NS 8176 [59] for comfort assessment,

- the recommendations [60, 61] of the United States Department of transportation (USDOT) for assessment of vibration impacts from high-speed train lines.

\subsection{Generation of the vibration}

Ground-borne vibration and noise are generated at the wheel/rail interface as indicated in Fig. 2 [62]. When the vehicle travels on the rail, the quasi-static and the dynamic forces arise from the contact points [63].

Quasi-static forces are the outcome of the self-weight of the train, and they dominate near the field up to one-quarter of the wavelength [5]. The quasi-static deflection of a typical track is a picture of such forces (and thus of the vibration generated). This is illustrated in Fig. 3 and can be deduced from a simple configuration (the track as an Euler beam on an elastic foundation), as in [64, 65]: 


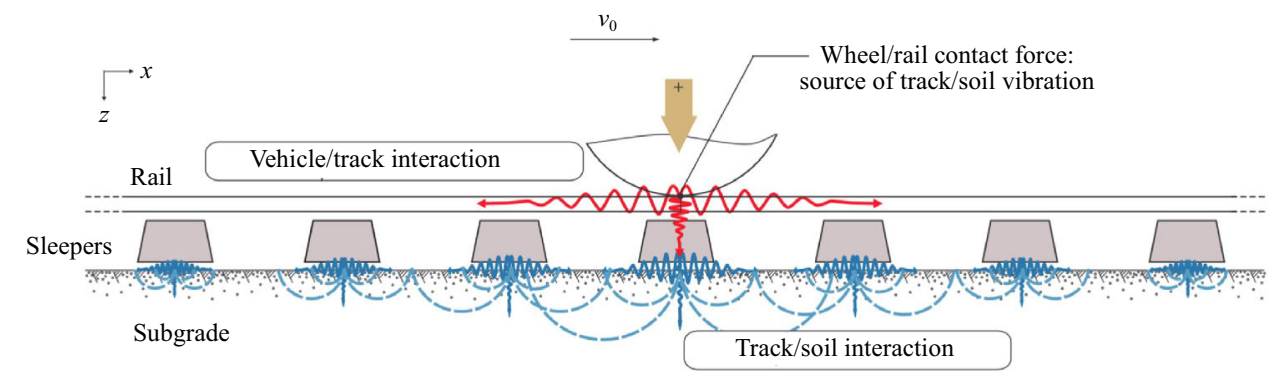

Fig. 2 Wheel/rail and sleeper/sub-grade interactions [62]

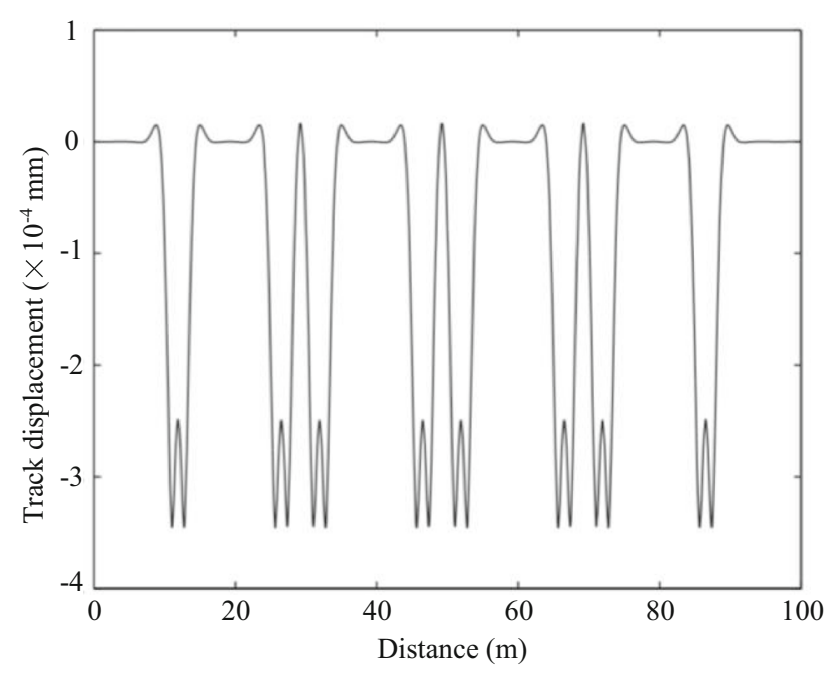

Fig. 3 Quasi-static track deflection

$$
\begin{aligned}
& w(x, t)=w\left(x-v_{0}, t\right) \\
& =\frac{P+m_{\mathrm{w}} g}{8 E_{\mathrm{r}} I_{\mathrm{r}} \beta^{3}} \mathrm{e}^{-\beta\left|x-v_{0} t\right|}\left[\cos \left(\beta\left|x-v_{0} t\right|\right)+\sin \left(\beta\left|x-v_{0} t\right|\right)\right],
\end{aligned}
$$

where $w(x, t)$ is the track deflection at position $x$ and time $t$, $E_{\mathrm{r}}$ is the rail Young's modulus, $I_{\mathrm{r}}$ is the second moment of area of the Euler beam, $P$ is the train load, $m_{\mathrm{w}}$ is the wheelset mass, and $v_{0}$ is the constant speed, whereas $k_{\mathrm{f}}$ is the stiffness for unit length of the Winkler foundation, $\beta$ is a constant defined as

$\beta=\sqrt[4]{\frac{k_{\mathrm{f}}}{4 E_{\mathrm{r}} I_{\mathrm{r}}}}$,

and represents the ratio between the foundation and the rail flexibilities.

On the other hand, the dynamic excitation is speed-dependent and is the outcome of components such as changes in stiffness due to sleeper displacement, irregularities at the wheel/rail interface (these are becoming less influential due to the improvement in the design and maintenance of the components) and soil support conditions. At the same time, the characteristic of the vibration waves produced by the rail traffic have specific properties depending on the type of line and/or vehicle. These are typically subdivided into the following four cases [64]:

- Underground trains-Generate vibrations with a higher frequency spectrum than over-ground tracks.

- High-speed trains - Generate elevated amplitude vibrations due to their increased speeds if the speed reaches one of the waves in the soil the vibration levels may rise.

- Urban tramways-Generate low amplitude vibration, but they can cause structural damages to buildings in their proximity.

- Freight trains-Generate high amplitude, low-frequency vibration (for their low speed) that can propagate to large distances from the source.

\subsection{Propagation of the vibrations}

Once the vibrations are generated at the wheel-track contact, they propagate through the soil as compression waves $(\mathrm{P}$ waves), shear waves (S-waves) and Rayleigh waves, see Fig. 4.

Primary or compression waves (P-waves) are longitudinal waves with the highest propagation velocity with the lowest energy transmitted. Whereas, shear waves (S-waves)

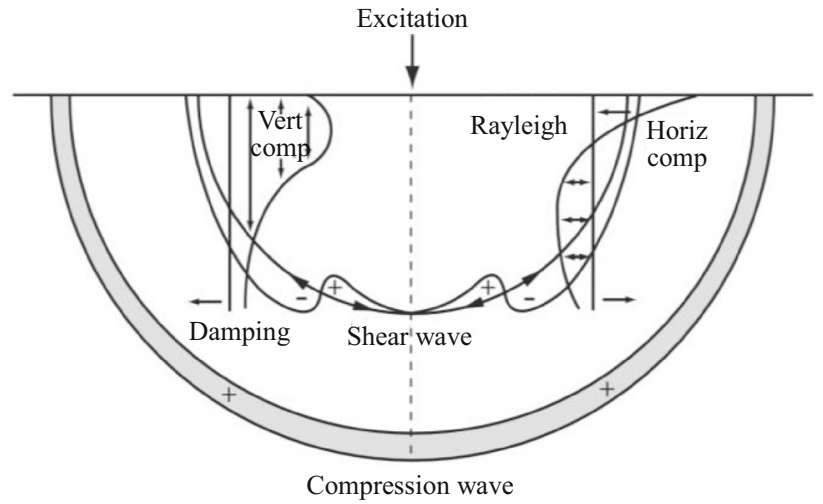

Fig. 4 Seismic wave propagation loaded on a circular footing (slice view-after [66]) 
propagate transversely, generally in an oblique direction into the soil $[41,67,68]$.

The analytical formulas to calculate P- and S-wave speeds are given in Eqs. (3) and (4), respectively [64].

$$
\begin{aligned}
C_{\mathrm{p}} & =\sqrt{\frac{\kappa+\frac{4}{3} G}{\rho},} \\
C_{\mathrm{s}} & =\sqrt{\frac{G}{\rho}},
\end{aligned}
$$

where $\rho$ is the density, $\kappa$ is the bulk modulus, and $G$ is the shear modulus of the soil.

Last, Rayleigh waves are the most important for the excitation of buildings, these are also known as surface waves because they occur at the surface of the soil. In underground lines, Rayleigh waves are arising from the ground surface reflection of P- and S-waves [69-71]. To notice that Rayleigh waves can only occur in a homogeneous half-space medium or in more complicated but with a single apparent velocity as a function of the frequency. Further to the aforementioned waves in theory others are possible.

\subsection{Impact and assessment of the vibrations on urban areas}

The impact and assessment of the induced vibration may have different effects depending on the intensity of the signal in all three directions (standards take generally the highest or the average value as reference). At the same time, it is important also to take into account the type of train (freight or passenger trains, see Table 1). In addition, some vibrations are classified as feeble (negligible), those that are below the threshold of perception [72], not relevant for the scope of this study. Instead, the noticeable groundborne vibrations could have the two following negative effects:

- Annoyance to humans,

- Damage to buildings and equipment.

Damage to buildings caused by railway induced vibrations are of secondary importance, and in case of occurrence causes mostly cosmetic damages (and rarely structural ones), these type of effects are taken into account for example by British Standard BS 7385-2 Code [73].

On the contrary, more important is the disturbance caused by railway passage to humans. According to the ISO 26312:2003 [51], the threshold of perception expressed in an RMS value (root mean square of the signal), which lies at a vibration strength of approximately $1 \mathrm{~mm} / \mathrm{s}$ at $1 \mathrm{~Hz}$ and 0.1 $\mathrm{mm} / \mathrm{s}$ at $10 \mathrm{~Hz}$ and higher (whereas the ground-borne vibration level caused by the rail traffic ranges between 10 to $80 \mathrm{~Hz}$ ). At the same time, it is important to notice that differences between individuals may occur depending on their sensitivity. In the ISO 2631-1:1997 [50], the absolute threshold of perception of weighted vertical vibration is stated to be around $0.015 \mathrm{~m} / \mathrm{s}^{2}$.

In addition to the vibration, there is the noise coming from the motion that the vibration itself is causing, the socalled ground-borne noise, for which the acceptable level can be derived from legal limits for environmental noise, which are $35-40 \mathrm{~dB}(\mathrm{~A})$ during the day and 25-30 dB(A) during night time. Recently, there are also studies that have state also some permanent effects in human health caused by these vibrations in addition to the only annoyance [19, 74-76].

An additional aspect, that can unfortunately increase the induced ground vibration levels toward aforementioned nearby buildings and humans, is the enhancement of the passengers' pleasure in order to provide an environment conducive to work, i.e., reading and writing skills are not diminished particularly on high-speed lines (see Table 2). Consequently, new designs and measures could twist between the two features.

\section{Concept of vibration isolation}

\subsection{On the use of transmissibilities}

Since the following part (Sect. 4) will describe the different mitigation measures, that are governed by principles on vibration isolation. In this section, the idea of vibration isolation will be presented by consideration of a singledegree-of-freedom system (Fig. 5). It can be seen as a rigid

Table 1 Frequency of typical vibration for each of the generating mechanisms, depending on train speed [7] (unit: Hz)

\begin{tabular}{llllllll}
\hline $\begin{array}{l}\text { Vehicle speed } \\
(\mathrm{km} / \mathrm{h})\end{array}$ & $\begin{array}{l}\text { Moving } \\
\text { load }\end{array}$ & $\begin{array}{l}\text { Track } \\
\text { unevenness }\end{array}$ & $\begin{array}{l}\text { Rail } \\
\text { corrugation }\end{array}$ & $\begin{array}{l}\text { Wheel } \\
\text { unevenness }\end{array}$ & $\begin{array}{l}\text { Wheel } \\
\text { polygonization }\end{array}$ & $\begin{array}{l}\text { Inter bogie spacing } \\
(8 \mathrm{~m})\end{array}$ & $\begin{array}{l}\text { Sleeper spacing } \\
(0.6 \mathrm{~m})\end{array}$ \\
\hline 40 & 3 & $1 / 100$ & 500 & $\geq 4$ & 100 & 1 & Multiple of $16 \mathrm{~Hz}$ \\
80 & 5 & $2 / 200$ & 1000 & $\geq 8$ & 200 & 3 & Multiple of $32 \mathrm{~Hz}$ \\
160 & 11 & $4 / 400$ & 2000 & $\geq 15$ & 400 & 5 & Multiple of $64 \mathrm{~Hz}$ \\
\hline
\end{tabular}


Table 2 Vehicle vibration effects on passengers

\begin{tabular}{lll}
\hline Effect on passenger & $\begin{array}{l}\text { Vibration frequency } \\
(\mathrm{Hz})\end{array}$ & References \\
\hline $\begin{array}{l}\text { Reading and writing } \\
\text { impairment }\end{array}$ & $0.8-8$ & {$[77,78]$} \\
$\begin{array}{l}\text { Reading impairment } \\
\text { Motion sickness }\end{array}$ & $1.25-6.3$ & {$[79]$} \\
\hline
\end{tabular}

body connected to a foundation by an isolator that has resilience (spring) and dissipation (damper) of the energy.

The performance of the isolator may be evaluated by the following characteristic values [80]:

- Absolute transmissibility $\left(T_{\mathrm{A}}\right)$, which is a measure of the reduction of transmitted force or motion afforded by an isolator,

- Relative transmissibility, which is the ratio of the relative deflection amplitude of the isolator to the displacement amplitude imposed at the foundation,

- Motion response, which is the ratio of the displacement amplitude of the equipment to the quotient obtained by dividing the excitation force amplitude by the static stiffness of the isolator.

These characteristics use steady-state displacement transmissibilities as a function of the frequency $f$ or the circular frequency $\omega(\omega=2 \pi f)$, and in practice, the absolute transmissibility is retained ( $\varphi$ is simply the phase of the signal). By considering a viscous damper, the transmissibility is given by Eq. (5):

$T_{\mathrm{A}}=\frac{X}{Y}=\sqrt{\frac{1+(2 \xi \Omega)^{2}}{\left(1-\Omega^{2}\right)^{2}+(2 \xi \Omega)^{2}}}$,

where $X$ is the amplitude of the mass response, $Y$ the amplitude of the foundation motion, $\xi$ the damping ratio,

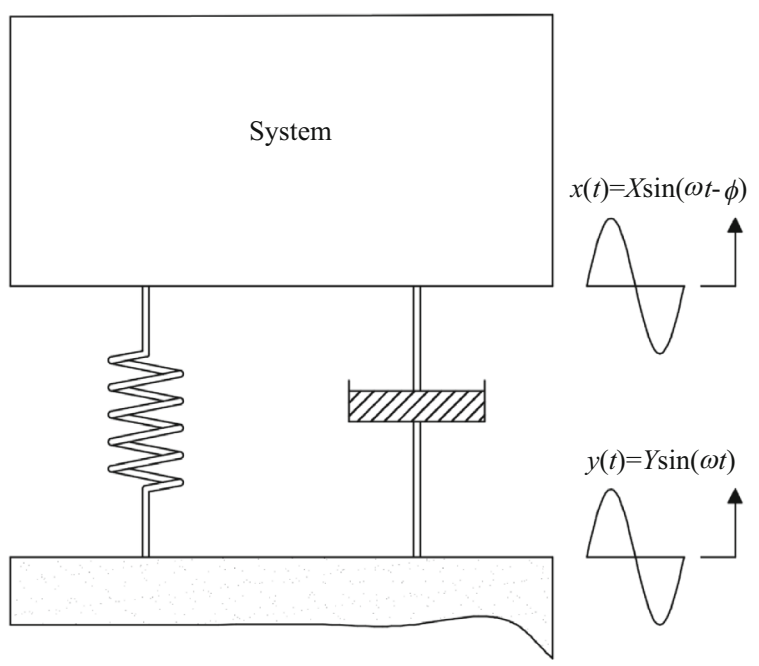

Fig. 5 Schematic diagram of vibration isolation systems and $\Omega$ the frequency ratio $\left(\omega / \omega_{\mathrm{n}}\right.$ where $\omega_{\mathrm{n}}$ is the circular natural frequency of the single-degree-of-freedom system).

In addition, it is important to have in mind that track mitigation measures are often characterized by a transmissibility curve (Fig. 6) as a function of the frequency. Three zones can be distinguished: zone 1 when the transmissibility is close to 1 (no effect of the mitigation measure); zone 2 when the transmissibility is greater than 1 (negative effect of the mitigation measure) and zone 3 when the transmissibility is lower than 1 (positive effect of the mitigation measure). Notice that for zone 3 , the smaller the damping ratio, the greater the vibration attenuation. The choice of support stiffness is, however, limited by the allowable vertical static displacements under the axle loads of the train, and some excitation frequency (covering zone 2) may be amplified. Such effects were generally observed for floating-slab systems [81-83].

Generally, the isolation becomes effective when the frequency ratio exceed $\sqrt{2}$. If the ratio is less than $\sqrt{2}$, the vibration may easily be amplified [84] and the isolator does more harm than good.

Notice that, due to the nature of material damping, viscous damping is not well adapted (since its effect increases with the frequency of motion), and hysteretic damping is preferred (no dependence with the frequency of harmonic motion), even it does present a real relationship in the time domain.

\subsection{Insertion loss}

In railway vibration, the effectiveness of the mitigation solutions described in Sect. 4 that are generally expressed in $\mathrm{dB}$ as insertion loss (IL) [7], i.e., the difference in vibration, between the original configuration and the

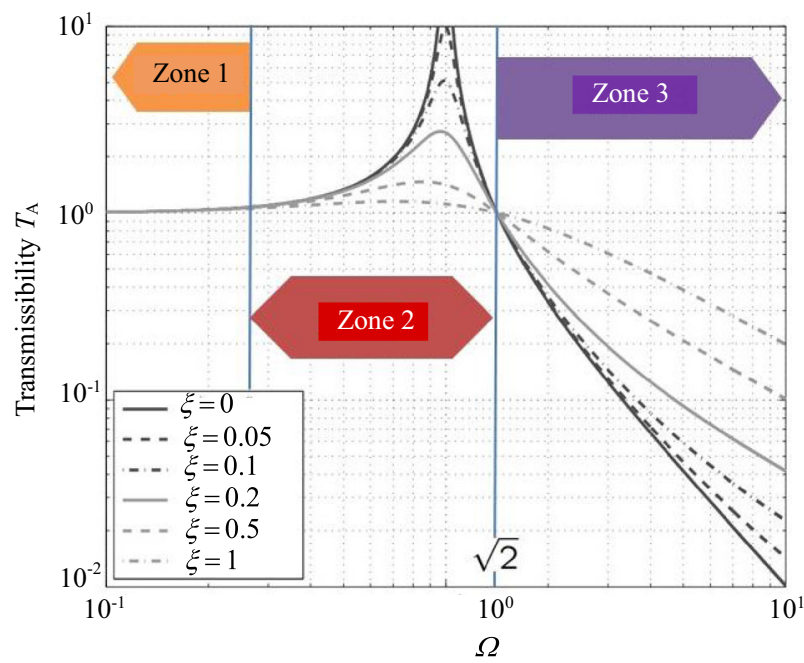

Fig. 6 The force transmissibility of a viscously damped SDOF system as a function of the frequency ratio $\Omega$ and the damping ratio $\xi$ 
application of the measure. In other words, the IL is obtained as shown in Eq. (6) from the ratio of the particle displacement of the configuration without and with mitigation measure $[85,86]$ :

$\mathrm{IL}=20 \log _{10} \frac{u^{\mathrm{ref}}}{u}$,

where $u^{\text {ref }}$ is the velocity without mitigation measure (nominal configuration) and $u$ the velocity after introducing the mitigation measure.

It is straightforward from Eq. (7) that if the displacement is half after inserting the mitigation measure the IL will be $6 \mathrm{~dB}$, while a negative value would only occur in case the measure has the opposite effect. The concept of vibration isolation presented in this section governs as a whole the mitigation measures, and therefore, the techniques introduced in the following section, and those will be evaluated according to the IL as anticipated.

\section{Mitigation systems}

In order to suppress and/or reduce the negative effects of ground-borne noise and vibration, different mitigation measures have been analysed and tested in the past years. These improvements can be applied to new infrastructure and/or existing ones, the different methodologies are to be compared both with their feasibility and the costs to be able to use them most conveniently. For the purpose of this research and to give a complete understanding of the state of the art of these improvements. In this section, the major available technologies will be illustrated and discussed exhaustively.

The mitigation systems can be applied in all three parts of the railway system, on the vehicle, on the track and on the transmission path (that is generally soil). It is also possible to make improvements directly at the receivers (i.e., buildings). Many of those have been tested in laboratories using full-scale and scaled models. But it comes out, due to the nature of the problem, that computer simulations after calibration using the experience from real projects are the right solution to proceed feasibly and competitively concerning physical models.

For simplicity, in this paper, the parts of the railway environment (where the mitigation measure are possible) are subdivided into four main subsystems: vehicle, track, transmission path, and receiver. Based on the different rail systems, the characteristics of the aforementioned components change from one to another. In literature are mainly subdivided in terms of new and retrofitting of existing lines, or in terms of surface and the underground lines.

\subsection{Improvement in the vehicle}

The vehicle dynamics play a crucial role in the generation of the ground-borne effects, principally when irregularities are present at the wheel-rail contact [87-89].

These days, rail vehicles are constructed using bogie system technology, with a single and double suspension, for the freight and passenger trains, respectively. Primary suspensions connecting the wheelsets to the bogie frame and are made with coil or rubber springs. Secondary suspension systems, located between the bogie and the car body, consist of elastomer elements, air spring or metal spring. Wilson et al. [90] demonstrated that a proper design of the bogie suspension can significantly reduce the levels of ground vibration. In general, vehicles with soft primary suspension produce lower levels of vibration than vehicles equipped with stiff suspensions [91-93]. It is also important to highlight that the way in which the vehicle affects the generation of the vibrations depends on the type of train and the technology that is used.

Despite the importance of the vehicle design parameters toward the generation of the ground-borne noise, the majority of efforts and research have been focusing on the other two sub-systems (track and ground) of the railway environment, which will be discussed later in Sects. 4.2 and 4.3. This is because the manufactures of trains focus on the car design within the ride comfort, stability and gauge in order to enhance the passengers' pleasure (see Table 2).

Therefore, the different measures that can be applied to the means of transportation have to deal with the reduction of the effects of the rail passage but at the same time have to maintain the train passengers comfort at the highest standards. The importance of improvement of the vehicle is crucial for the ground-borne vibration since this effect is arising between the track and wheel contact, with the latter being a component of the train.

The principal measures to control and/or mitigate the ground-borne vibration coming from the vehicles will be presented in the sub-section and are the following:

- Improving wheel roundness,

- Reduction of the unsprung mass,

- Reduction of speed,

- Resilient wheels.

When the main contributor in the vehicle is identified, it is possible to design the vehicle so as the dynamic forces acting on the track are reduced. It should be noted that wheel out of roundness and the unsprung mass of a single wheel are often the dominant excitation mechanisms [94]. 


\subsubsection{Improving wheel roundness}

Wheels out of roundness are one of the main causes of excessive vibration and are the result of the manufacturing process or repeated loading at high frequencies [95]. The most common manifestation is the formation of wheel flats, caused primarily by train breaking/deceleration, and this results in high-frequency impact force whenever the corners of the wheel flat impact the rail during the rotation. Instead, Fig. 7 shows an example of wheel polygonalization in the first-, second- and third-order. The orders here are just taken as a reference. However, these can increase up to $23 \mathrm{rd}$ as reported by $\mathrm{Wu}$ et al. [96] or even more.

This can be achieved with good maintenance of the wheels, improvement of the sliding protection and steel quality. In particular, re-profiling, a high-quality wheel grinding program ensures the reduction of noise levels in the range of 5 to $10 \mathrm{~dB}$.

\subsubsection{Reduction of the unsprung mass}

The unsprung mass is defined as the set of the loads generated by suspensions, wheels and bogies frames. This mass laying directly on the rail beams is the main cause of the damage to the tracks. Therefore, its reduction becomes relevant in terms of track and infrastructure damage and consequently with respect to the reduction of the vibrations level. However, the decrease of this mass is difficult to achieve due to safety criteria, wheels life and the vehicle dynamics design.

The wheel-set mass is generally in the range of $700-3500 \mathrm{~kg}$, from small-diameter wheels on freight wagons to large diameter locomotive wheels. Its reduction can be obtained by the optimization of the cross-section in its shape and/or material and is generally limited to 5\%$10 \%$ of the nominal wheel mass, with which is possible to achieve a vibration reduction of $2-4 \mathrm{~dB}$ in the long-term [94]. In addition, the reduction of the radial thickness would reduce wheel mass significantly but at the same time influence the number of re-profilings, wheel life and production costs.

\subsubsection{Reduction of speed}

A central role in the generation of ground-borne noise and vibration plays vehicle speed. Therefore, as its value changes the amount of ground-borne vibration and noise is affected. In particular, by reducing the train speed by a factor of two it is possible to reduce vibration levels approximately up to $6 \mathrm{~dB}$ [61].

For example at the beginning of the 1990s in the project of the high-speed trains (HST) at Ledsgard (Sweden) [97], different interventions were made in order to mitigate the generated vibrations. Traffic with HST started in spring 1997 with a speed of $200 \mathrm{~km} / \mathrm{h}$. Shortly afterwards, excessive vibrations were observed in some sites. These vibrations were in the order of ten times greater than those measured earlier from heavy train traffic in soft soil conditions and had been regarded as the worst case. Train speed was reduced to $160 \mathrm{~km} / \mathrm{h}$ and later to $130 \mathrm{~km} / \mathrm{h}$. Thanks to these reductions of the operational speed of the HST line from 190 to $130 \mathrm{~km} / \mathrm{h}$ it was possible to achieve an IL of $26 \mathrm{~dB}$ at 12 meters from the source, as reported in Fig. 8.

In general, when the train speed is approaching the Rayleigh wave speed of the transmission path it is possible to have considerable growth in the track vibration and consequently an increase in the ground-borne effects $[98,99]$ as in the case of the aforementioned Ledsgard project. Experimental demonstration of these effects has been redrawn for three sites located in Sweden, UK and Netherlands, by Connolly et al. [64, 100] as depicted in Fig. 9. It is straightforward that as the normalized speed (train velocity/Rayleigh wave speed) approaches unity, the track displacement increases exponentially.

In addition to the speed of the train, many other factors influence the vibration propagation, such as types of railway vehicles, transport type (passenger or freight), track
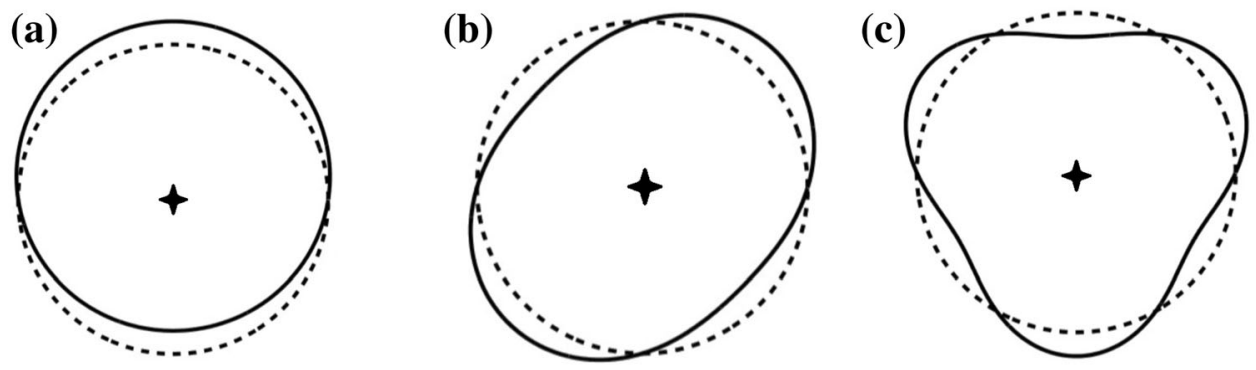

Fig. 7 Examples of different orders of wheel out-of-roundness: a first-order out-of-roundness ( $\theta=1$, eccentricity), b second-order out-ofroundness $(\theta=2$, ovality) and $\mathbf{c}$ third-order out-of-roundness $(\theta=3)$ 
type and others [101]. In particular, this has been discussed by Thompson et al. [62] that presented a prediction of the wavefield generated by a point load of constant unit amplitude for three load speeds: 80,168 and $250 \mathrm{~m} / \mathrm{s}$ as depicted in Fig. 10.

Figure 10a shows the wave-field generated by the load moving at a speed that is below the wave phase velocities of the surface waves, here the wave speed is very low. Whereas, when the load speed is close to the Rayleigh wave speed of the upper layer, in Fig. 10b, the wave-field generated changes and the displacement amplitudes are significantly larger. If the velocity increase up to $250 \mathrm{~m} / \mathrm{s}$, as in Fig. 10c, the waves generated travel with significant amplitude away from the load.

Therefore, in order to get advantages from the reduction of the speed would be necessary to find the less impacting speed during the motion, depending on the type of train, type of transmission path (that will be discussed in Sect. 4.3), and other components. Even if vibration levels can be reduced up to $6 \mathrm{~dB}$, the numerous factors involved in the process do not make speed reduction among favourite choices when developing mitigation systems. On the other hand, a disadvantage of this approach is that it has a high cost in a long time because the line capacity is reduced.

\subsubsection{Resilient wheels}

Resilient wheels are more effective in eliminating wheel squeal on tight turns where reductions of 10-20 dB [61]. However, it is also possible to have a reduction in vibration in the range of 3-6 dB.

Figure 11 shows the positive effect of changing the stiffness of resilient wheel equipping trams in order to reduce the transmitted ground vibrations, in terms of IL, notice that the standard wheel have a stiffness of $145 \mathrm{MN} / \mathrm{m}$

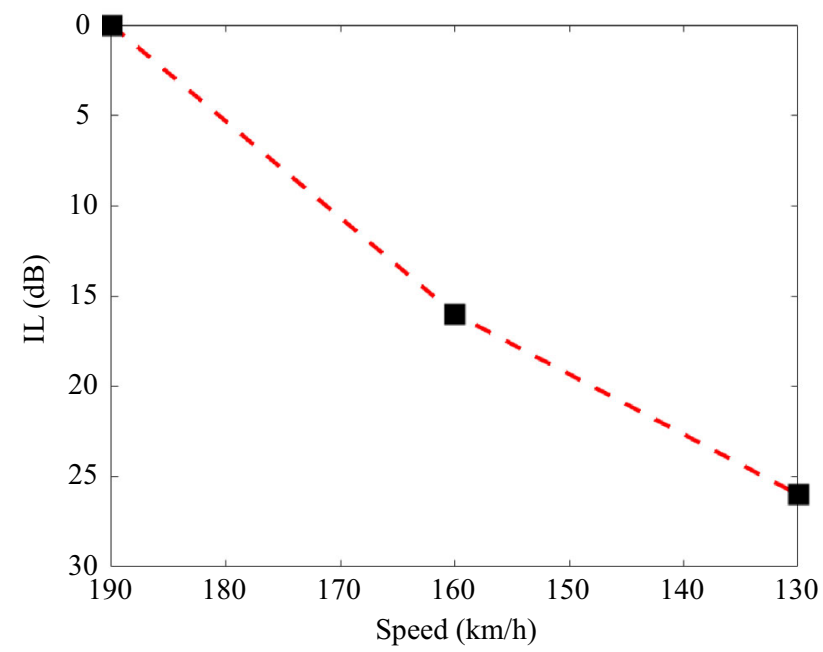

Fig. 8 Velocity effects on IL of HST at $12 \mathrm{~m}$ distance, data from [61]

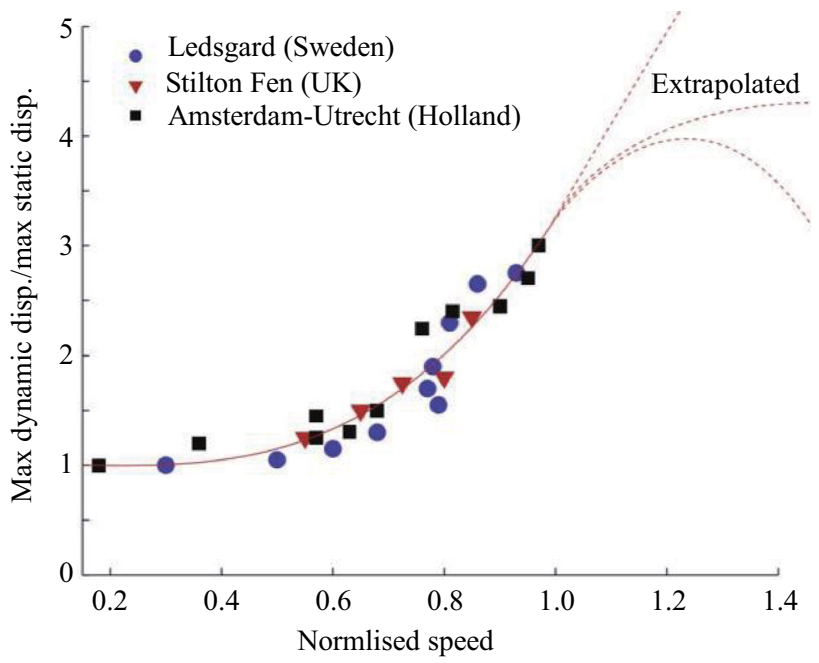

Fig. 9 Experimental critical velocity effects [64]

decreased in the illustrated case to 13 and $18 \mathrm{MN} / \mathrm{m}$. This also demonstrates the real interest of a compound vehicletrack-soil model in the design of this kind of wheel [102].

\subsection{Improvement in the track}

In urban areas where the railway effects are of more concern, it is quite logical and straightforward to understand that mitigation measures at the source (vehicle and wheeltrack) are more convenient than the ones applied both in the path (ground) and in the receiver (surrounding resident and constructions). This is for the reason that by mitigating at sources all the surrounding receivers are protected, while with the protection at the receivers it is necessary to produce a system for each receiver. On the other hand, in areas where we have less neighbourhood might be convenient to intervene in the receiver.

Keeping the conflicts that the design of the vehicle could have in terms of internal comfort, and the generation vibration the improvements in the track achieves a crucial role in the quest to mitigate negative effects coming from the rail traffic. Additionally, as it can be seen in Fig. 12, among the numerous dynamic excitations that contribute to railway vibrations, the excitation due to the vehicle are found at low frequencies, and the excitation associated with the wheel, rail and track is found at higher frequencies.

Before introducing the improvements that can be applied to the track, it is worth to briefly present the track system and its component [103]:

- Rail is the main part of railway track, acts as two parallel lines.

- Rail pad is designed between the sleeper plate and foot of the rail, generally made by an elastic polyurethane 

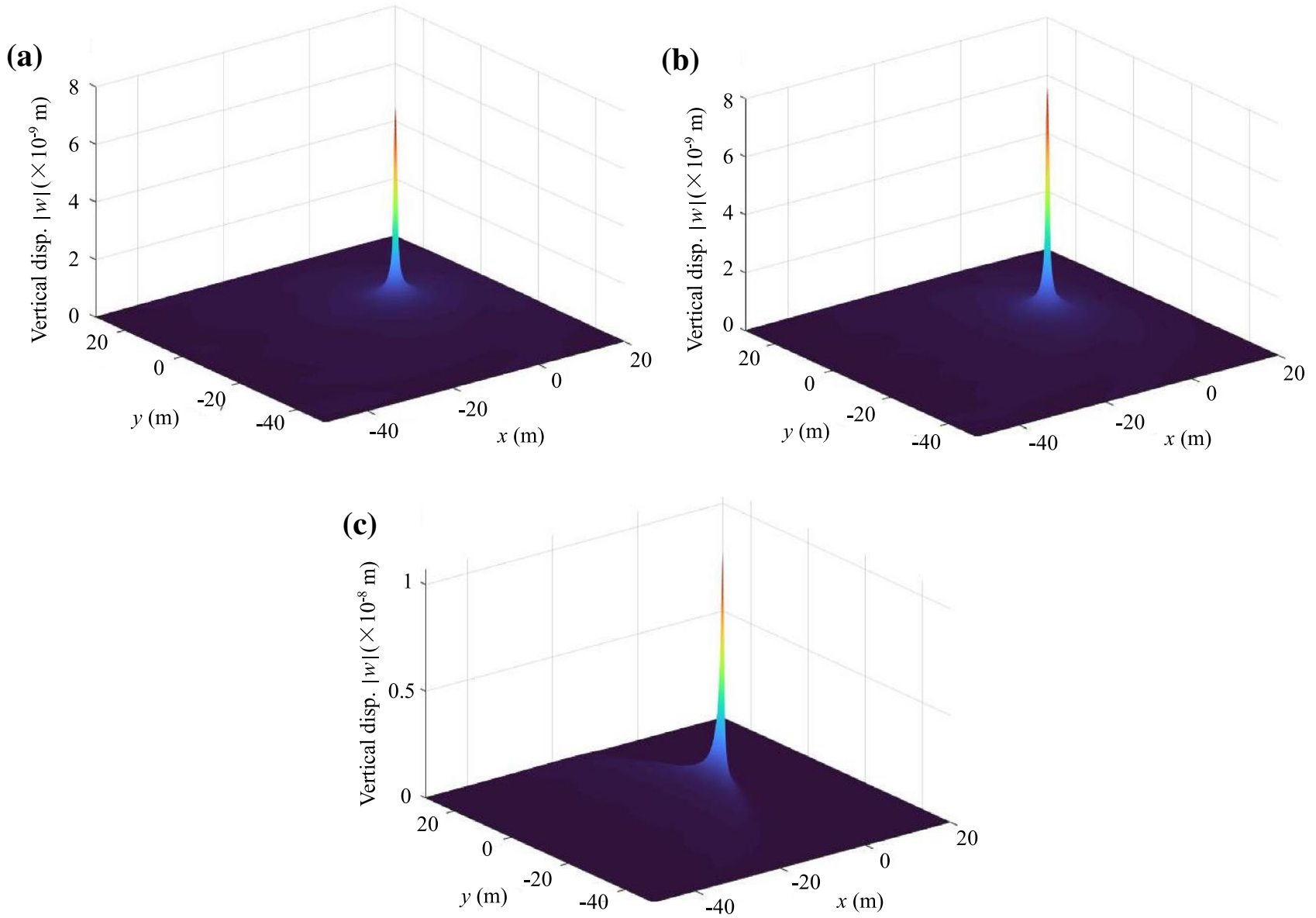

Fig. 10 Displacement pattern in the moving frame of reference for a single non-oscillating point load on the ground surface moving at: a at $80 \mathrm{~m} / \mathrm{s}$ (below the wave speeds in the ground); $\mathbf{b}$ at $168 \mathrm{~m} / \mathrm{s}$, close to the Rayleigh speed of the upper layer for this ground system; $\mathbf{c}$ at $250 \mathrm{~m} / \mathrm{s}$

mat. Together with spikes and the fasteners joining the steel rails to the sleepers.

- Sleepers is laid perpendicular to steel rail. Railway sleeper can be properly deformed to trimmer pressure when the train passes through and are generally of three types (wooden, steel and concrete sleeper).

- Ballast bed is a layer of free-draining coarse aggregate used as a bed elastic support for sleepers.

An important factor for the ground-borne effects is the overall track stiffness. Indeed if too low there is an increase in the deformation of the soil and ballast, while on the contrary when the stiffness is too high a corrugation is easier to be generated [104]. Additionally, if the stiffness has radical fluctuations over the track section then also in this case track deterioration and vibration are increased [105]. The values of stiffness change from country to country based on types of traffic that are expected (e.g., freight or passenger transport), consequently it is difficult to fix an ideal value of the stiffness since generally, the lines host various types of trains. Therefore, track imperfection and degradation (not only due to track stiffness) are crucial to the track vibrations.

Therefore, a correct selection of these elements (rail, fastening, sleepers, ballast) plays a central role in diminishing the formation and propagation of vibration. Increasing the flexibility of the superstructure components raises their ability to damp (dissipate) vibration generated at wheel-rail interface [106].

\subsubsection{Rail enhancements}

The irregularity in the track and the ballast can be an important source of vibration. Indeed, a good track alignment can provide a $10 \mathrm{~dB}$ reduction for the ground-borne noise for speeds at $320 \mathrm{~km} / \mathrm{h}$, therefore, maintenance to the rail plays an important role in the vibration mitigation.

Embedded rail systems are also an alternative (Fig. 14d), typically used in urban tram lines. In these systems, the rail is embedded in a concrete slab which is then either filled by pouring out elastic embedding material (at the bridges steel moulds are applied) or by the installation of prefabricated 
(a)

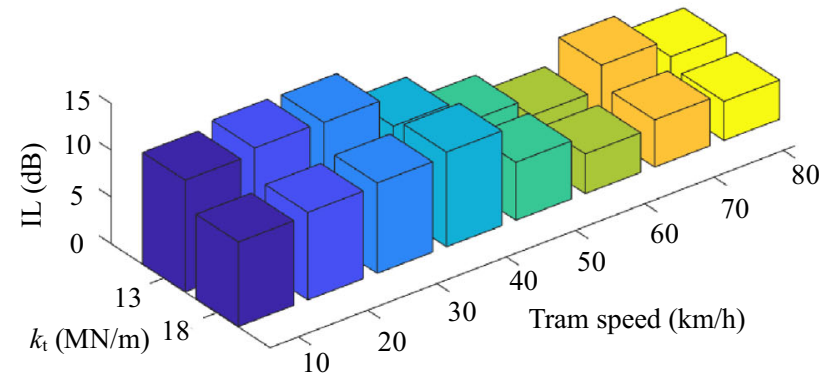

(c)

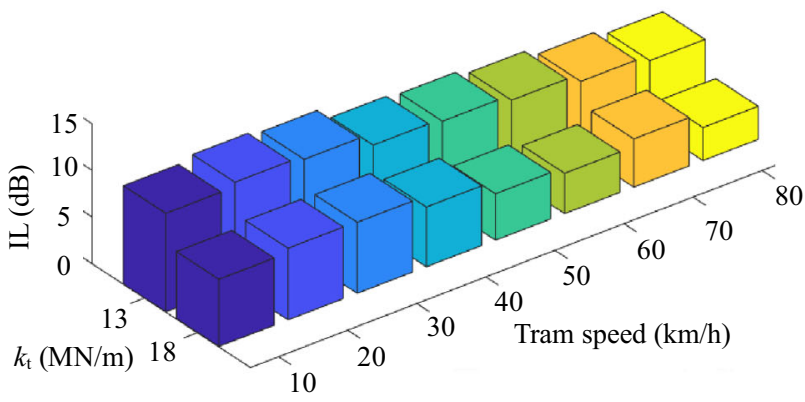

(b)

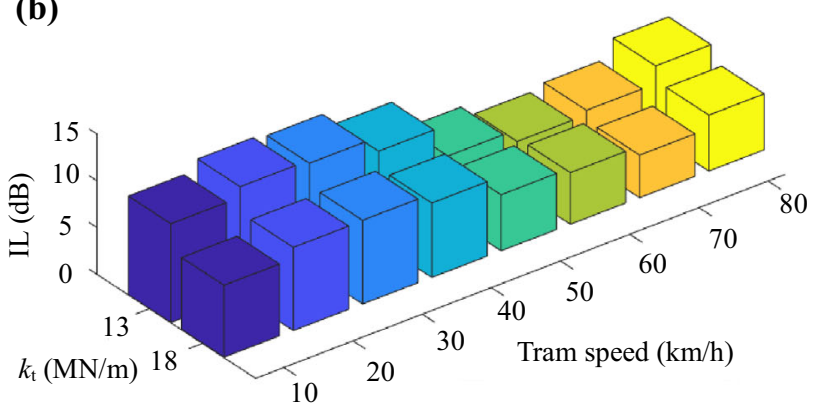

(d)

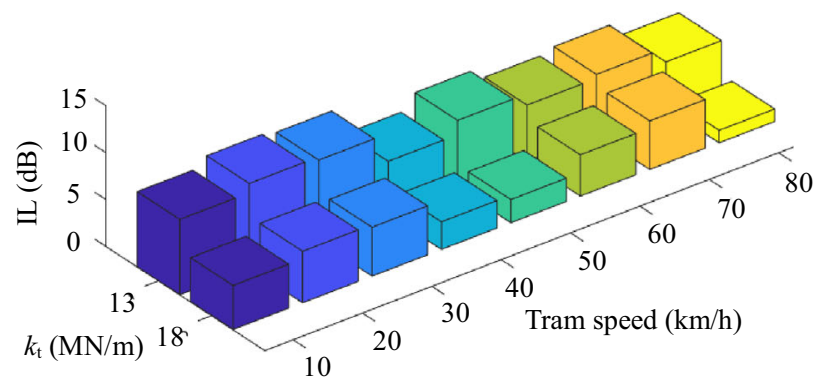

Fig. 11 Effects of changing wheel resilient material stiffness (from $145 \mathrm{MN} / \mathrm{m}$ to 13 and $18 \mathrm{MN} / \mathrm{m}$ ) on ground vibration level. IL as a function of the wheel stiffness in the case of the T2000 tram circulating in Brussels region: $\mathbf{a}$ at $4 \mathrm{~m}$ distance; $\mathbf{b}$ at $10 \mathrm{~m}$ distance; $\mathbf{c}$ at $16 \mathrm{~m}$ distance; $\mathbf{d}$ at $20 \mathrm{~m}$ distance

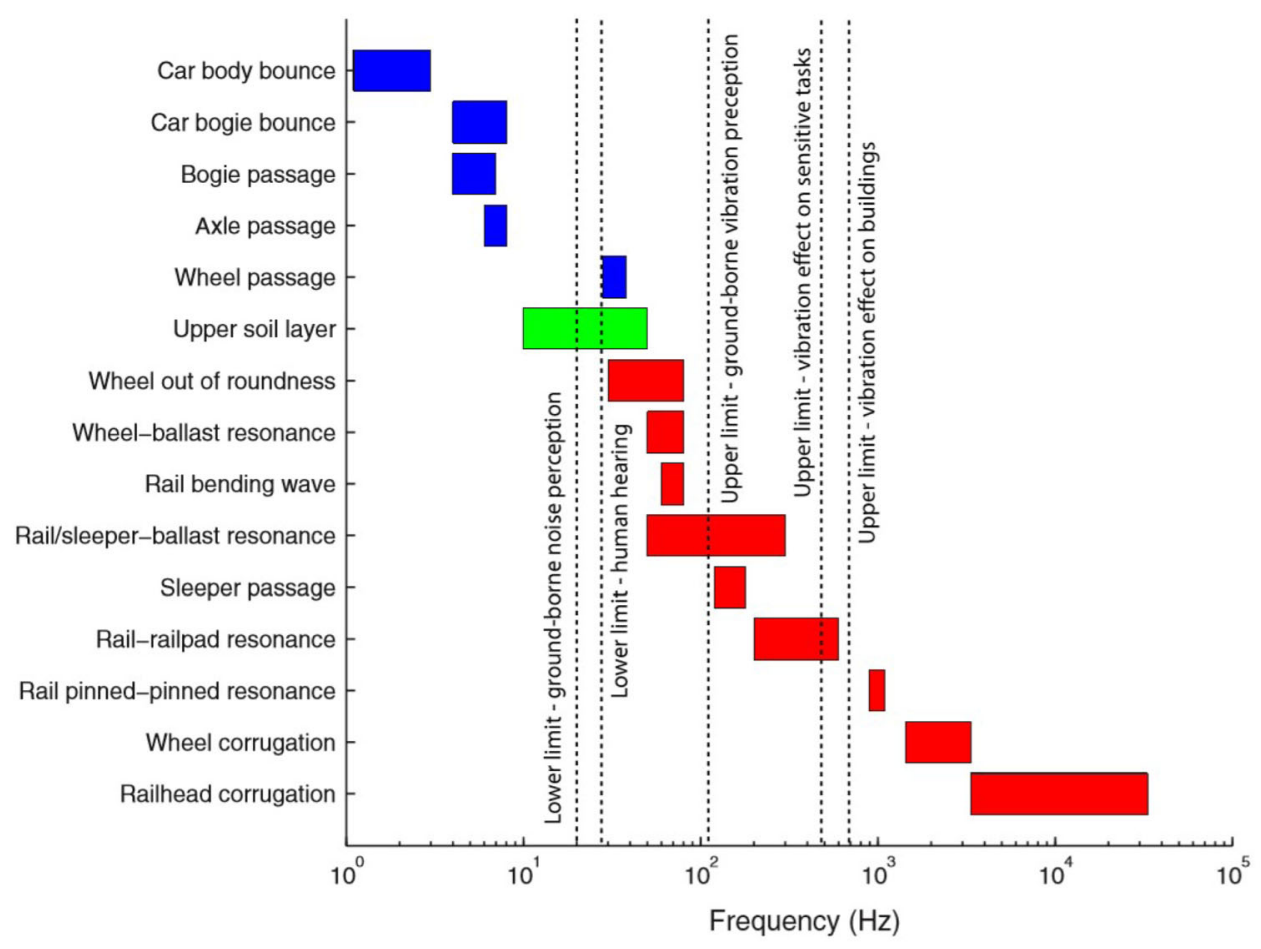

Fig. 12 Typical frequency ranges of excitation [64] 
rubber parts around the rail web, with a wedge on either side to keep the rail in place. Eszter et al. [107] showed that the elimination of metal-to-metal contact contributes to a reduction up to $8 \mathrm{~dB}$ in the frequency range $5-200 \mathrm{~Hz}$; Whereas, Lakušić et al. [106] showed a vibration reduction between 12.9 and $18.6 \mathrm{~dB}$ in a tram line after implementation of continuously embedded rails depending on the tram vehicle type.

Rail dampers can also be used for vibration mitigation. These are prefabricated passive elements in steel material, which are fixed to both sides of the rail web serve to reduce the vibration of the rails. Rail dampers are usually installed between every sleeper in problematic areas of the track. Studies conducted by German (DB) and French (SNCF) Railways, at the rail track sections with rail dampers installed, showed an in vibration up to $9 \mathrm{~dB}$ [108].

\subsubsection{Fasteners enhancements}

Rail fasteners are used mostly, even if several improvements have been made over the years are the one presented a long time ago, named resilient rail fasteners. However, with the recent application of new designs where the rail is supported by resilient blocks such as in the Thameslink project in London, it has been possible to have a reduction of $13 \mathrm{~dB}$ in ground-borne noise [109].

Additional studies have demonstrated that high resilience fastening systems (Fig. 13a), in which elastic elements supporting the rail at the web prevent direct contact between the rail foot and sleeper, allows significantly greater vertical deflection of the rails under operation, gaining a low vertical stiffness of the entire system that reduces vibrations by $5-10 \mathrm{~dB}$ at frequencies above $\mathrm{Hz}$ [61]. Instead of rail fasteners with a highly resilient under base-plate pad (Fig. 13b), where the resilient pad is precompressed with a load equivalent to $80 \%$ the normal static load on the fastener during vehicle passage [110], vibration isolation of $20 \mathrm{~dB}$ is ensured with range frequency between 25 and $20 \mathrm{~Hz}$ [111], to notice that in this last case the spring is unloaded during the train passage and as a result, there is no vibration transmission to the lower parts of the track.

\subsubsection{Sleepers and ballast enhancements}

The sleeper can be installed in concrete or wood. Concrete sleepers are the most used type because of different economical advantages (simpler installation, greater durability, lower maintenance and operation costs), but wooden sleepers present a higher vibration damping capacity $[113,114]$. The studies made by FTA [61] showed a vibration reduction by $5 \mathrm{~dB}$ when using wooden sleepers.

At the same time, there are also other important improvements that can be done just under the track in order to achieve vibration attenuation, such as by placing the elastomeric pads between the sleepers and the ballast bed. This elastomeric pad is usually composed of two layers of different material, the upper made by viscoelastic rubber with high vibration damping ability and the lower layer is a coarse geotextile that serves to prevent possible upper layer damage from impressing of crushed ballast material [106].

UIC stated in [7] that for pads under the sleepers a reduction of 8-20 dB can be archived. These pads have the advantage that they are easy to install during a sleeper renewal operation since they are delivered already fixed to the bottom of the sleeper [115]. Whereas, for the ballast mats (that can be applied to both the surface and underground systems) the reduction ranges from 3 to $15 \mathrm{~dB}$. However, if a ballast mat is too soft there is a risk that the ballast layer becomes more feeble when solicited to the vibration produced by the passing train. Therefore, this could compromise the ride quality unless rigorous maintenance is performed (increasing in costs) [116].

\subsubsection{Alternative track technologies}

In the track improvements, the technology of the track itself plays a crucial role and, in addition to the classical

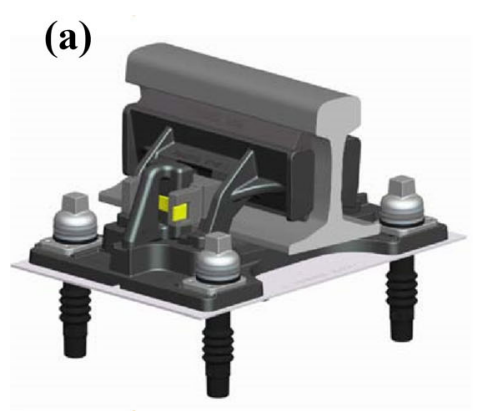

(b)

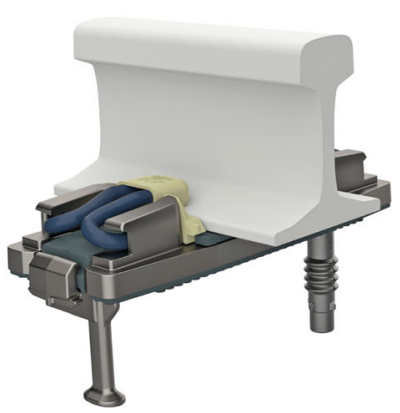

Fig. 13 Possible resilient fastening system (with courtesy of Pandrol) [112]: a high-resilience fastening system and b resilient pre-load fastening system 
ballasted track, there are other approaches with different track design concepts projected in order to mitigate the ground-borne noise and vibration.

The most common measures to mitigate the groundborne effects in ballasted track presented above and some possible alternatives (which will be presented further down) are depicted in the order of cost upwards from top to bottom, in Fig. 14.

In reference to vibration damping, track structures with ballast bed are better than the track structures on special reinforced concrete slabs the commonly named slab tracks (where the ballast is replaced by a rigid concrete track slab which transfers the load and provides track stability), with up to $3-5 \mathrm{~dB}$ of enhancement [117]. The main disadvantage of this type of track construction, compared with tracks laid in ballast bed, is its greater rigidity, which results in increased vibrations. Further reduction of the vibration propagation can be achieved by increasing the height of the ballast bed, the German Railways (DB) [117] showed that an increase in the ballast bed height from the usual 30 to $75 \mathrm{~cm}$ can reduce the vibrations by $6 \mathrm{~dB}$ at frequencies lower than $10 \mathrm{~Hz}$.

Another alternative to ballasted tracks is the floatingslab tracks. These are special types of slab tracks with the so-called mass-spring systems principle, here the track is mounted on a thick concretes lab that rests on rubber bearings, glass fibre or steel springs. With such designs, the highest possible mass is added above the track spring to form a system with a very low resonance frequency.

Floating-slab tracks are typically used to manage the vibration and ground-borne noise from underground trains where a large reduction is required [118]. As well as the greater construction cost of the track form itself, the great expense can come from any increase in the diameter of the tunnel that has to be made to accommodate sufficient mass for the floating lab. The slab may be cast in-situ, resulting in a continuous piece of concrete, or maybe constructed in discrete precast sections laid end to end. Continuous slab designs usually have a lower deflection for a given resonance frequency and make maximum use of the tunnel space but have the disadvantage that they are harder to design in such a way that the slab mounts can be replaced [62].

Studies have shown that the natural frequency of such structures lies between 8 and $12 \mathrm{~Hz}$, depending on the material used and the total weight of the structure. The application of floating slaps and other mass-spring systems allows the vibration reduction by $10 \mathrm{~dB}$ with frequencies above $16 \mathrm{~Hz}$ or by $25 \mathrm{~dB}$ with frequencies of $125 \mathrm{~Hz}$ [16]. Whereas vibration measurements performed on a floating track with ballast bed and spacing of the springs in $3,7 \mathrm{~m}$ showed that the system has $90 \%$ vibration isolation efficiency, and the transmission loss was about $40 \mathrm{~dB}$ between 10 and $100 \mathrm{~Hz}$ frequency [107].

This measure of allocating the rail line in tunnels has the greatest reduction of noise and vibration and can achieve up to $40 \mathrm{~dB}$ as aforementioned [107, 119]. However, this technology can present some limitations due to the high costs of construction, service and maintenance of the tunnel.

An additional measure, that plays an important role when dealing with ground-borne vibration and noise mitigation, is the dynamic vibration absorber (DVAs) [27, 120-122]. DVA is a vibration system that combines dampers and springs, to absorb and dissipate the vibration energy, the rubber layers bonded with the rail waist are mainly used to perform as the distributing elastic components of the DVA; the steel plates are used as the quality layer and the constraints layer to form the distributing power quality of DVA, together with the rubber damping layer. Then the distributing elastic components and distributing power quality can jointly constitute a set of distribution parameters of the dynamic vibration absorber. The DVA can absorb the vibration and prevent the noise radiation when the rail waist is vibrating [120]. The DVA system can be an effective measure to address the groundborne effects and can reduce between 5.3 and $6.6 \mathrm{~dB}$ depending on the type of soil and the train speed [123].

\subsection{Improvement along the path}

Another important part of the rail environment, where it is possible to intervene in order to mitigate the effects of rail traffic, is the transmission path. Here, the elastic waves travel from the source to the receiver (see Sect. 2.2). In most cases, when referring to the transmission path we have soil and/or rock materials.

Measures in the transmission path are typically applied in the surface train, where surface waves are the main contributor for the ground-borne effects, because for the Pand S-waves and the parts of the buildings that are below the ground level these measures would not be worthwhile. The aim of the measures insert between the track and the adjacent building is to act as a barrier, diverter or damper of the vibration waves that travel from the source with the scope of minimizing and/or cancel their effects at the receiver.

In literature, there are different methods/technologies that can be applied between the source and the receiver, here to follow an introduction of the most common.

\subsubsection{Increasing the distance}

An obvious and effective way to reduce ground-borne noise and vibration is by augmenting the distance 
(a)

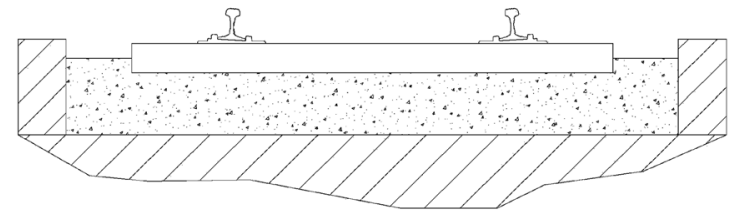

(c)

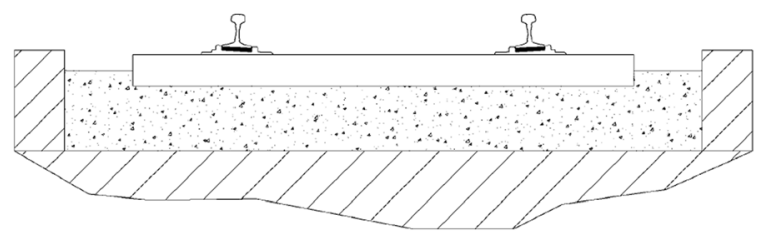

(e)

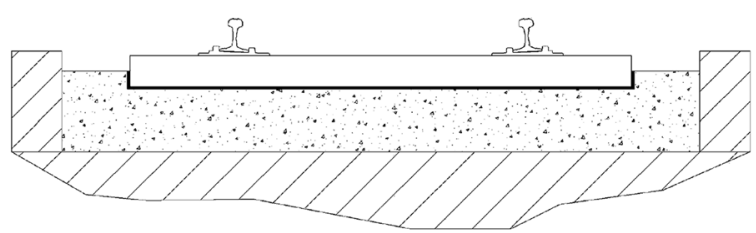

(g)

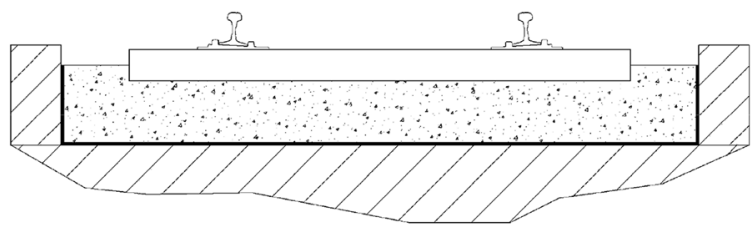

(i)

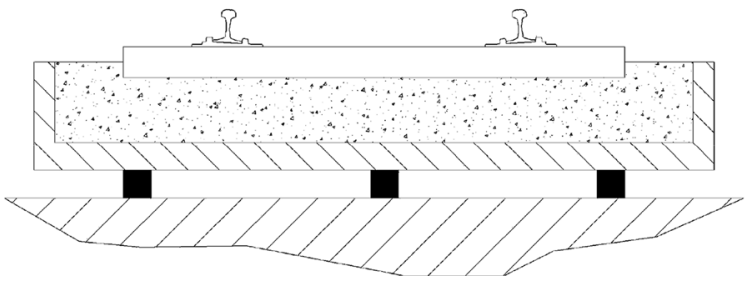

(b)

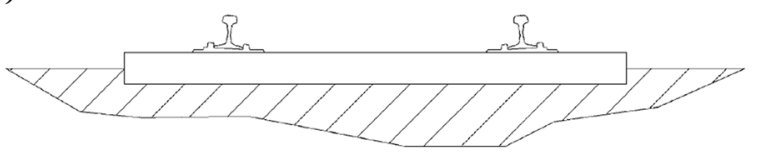

(d)

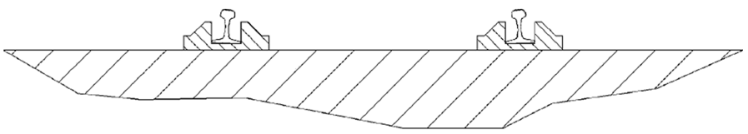

(f)

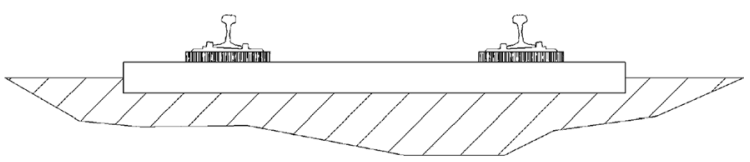

(h)

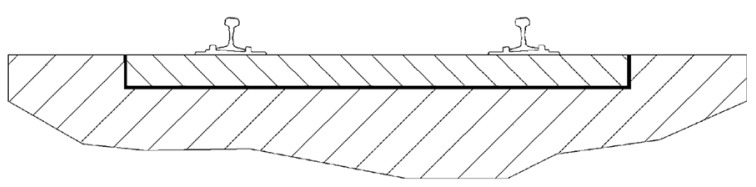

(j)

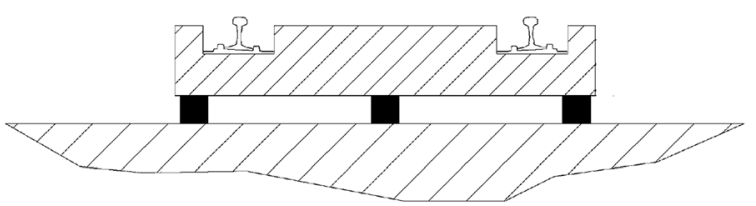

Fig. 14 Generic track form layouts, redrawn from ISO 14837:2005 [8]: a ballast; b directly fastened rail; c ballast with soft pads/continuously fastened rail; $\mathbf{d}$ embedded rail; $\mathbf{e}$ ballast with sleeper soft pads; $\mathbf{f}$ resilient base-plates; $\mathbf{g}$ ballast with under-ballast mat; $\mathbf{h}$ floating track slab (continuous support); $\mathbf{i}$ floating ballast trough; $\mathbf{j}$ floating track slab (discrete support)

between the track and the receiver. However, this measure is applicable only in some cases when urbanization permits it, and the cost of the free land is cheaper than other mitigation measures. At a distance of $500 \mathrm{~m}$ from the rail track, people no longer perceive the rail traffic vibrations [124, 125]. The Federal Transit Administration [61] gives some guidelines on how to calculate the velocity levels according to the distance from the source.

\subsubsection{Embankment}

Embankments are constructions that allow railway lines to pass at an acceptable level and gradient over low lying ground. Their principal and the original role was to keep track horizontally. However, their use is showing good behavior in the mitigation of ground-borne effects coming from the railway traffic. A prediction model was presented by Connolly et al. [126] and Ju et al. [127].

Studies such as the one did by the FRA [128] showed that by situating rail tracks on an embankment, a reduction of noise at the point of emission for up to $5 \mathrm{~dB}(\mathrm{~A})$ can be achieved if the height of the embankment is at least $3 \mathrm{~m}$ [106]. Whereas, Olivier et al. [129] demonstrated how the subgrade configuration affects the transmission path: embankment with specific material stiffness can play the role of a waveguide by trapping energy within it (Fig. 15). The latter was confirmed by other studies that demonstrated similar results $[126,130,131]$.

\subsubsection{Protection barriers}

The barrier is generally an introduction of material or geometry without material as in the case open trench in the 
soil between the source and the receiver that thanks to its characteristics such as density, stiffness, weight, etc., are able to deviate/damp the waves[132]. Different barriers are available with different shapes and materials.

The use of open trenches (cuts in the soil filed with air as depicted in Fig. 16a), to moderate the effects of ground vibration is a methodology that is commonly used [133], that acts by diffracting below the barrier the vibration waves as the acoustic barrier with air-borne sound. Studies have shown that the reduction in vibration at a frequency of $30 \mathrm{~Hz}$ requires a minimum trench depth of $4.5 \mathrm{~m}$ [61]. Good results are obtained when the depth of the trench is at least half the Rayleigh wavelength; for example, Thompson et. al [134] obtained a reduction of $12 \mathrm{~dB}$ with a trench depth of 0.6 times the wavelength of Rayleigh waves.

Open trenches are limited to a certain depth due to stability reasons and the presence of water that can compromise their operation. Therefore, it can be useful to use soft or stiff material (see Fig. 16b) to fill the trench. The material used to feel the trench should be as low as possible in order to limit the transmission of the vibration.

For soft wave barriers among the ones that are available in the literature:

- Gas cushions, reduction around 6-10 dB when the depth is equivalent to the wave length [135],

- Rubber chips, express a high reduction that exceeds 12 $\mathrm{dB}$ [136],

- Polystyrene, at $20 \mathrm{~Hz}$ reduction of $12 \mathrm{~dB}$ and at $40 \mathrm{~Hz}$ reduction of $6 \mathrm{~dB}$ [137],

- Water, named also ditches not deeper than 2-5 $\mathrm{m}$ have an effectiveness of up $3 \mathrm{~dB}$ [7].
For the stiff wave barriers, the stability is not anymore a problem as in the previous type of barriers [138]. For these categories of barriers, the following materials are used:

- Steel and concrete piles (as in Fig. 16e), depending on the number of pile and cross-section, the reduction is around $80 \%-90 \%$ of the open trench [139].

- Sheet pile wall, at $25 \mathrm{~Hz}$ the insertion loss values around $3 \mathrm{~dB}$ [138].

- Jet grouting wall, vertical vibration up to $45 \%$ were achieved at distances up to 60 metres from the track [7].

An alternative solution to limit the propagation of vibration waves in urban areas where it is not possible to develop trenches is underground barriers near the rail track. These barriers are generally obtained by mixing live lime or cement into the existing soil.

In a similar way, phononic crystal barriers represent a promising innovative anti-vibration method [71]. Those are also well-developed for the acoustic barriers (air-borne noise), but their use to contrast the ground-borne effect is coming out in recent times. Generally, the barriers consist of a periodic buried structure, made of stiff inclusion (e.g., concrete), this organization produces the so-called crystal effect that manipulates the vibration waves. Albino et al. [71] for example have demonstrated that attenuation up to $18 \mathrm{~dB}$ can be reached that is next to the values that can be achieved by using a wall (that on the contrary is much more expensive). Castanheire-Pinto et al. [86] played with the orientation of the inclusions, and they proved that is less effective to arrange the inclusion vertically since doing so

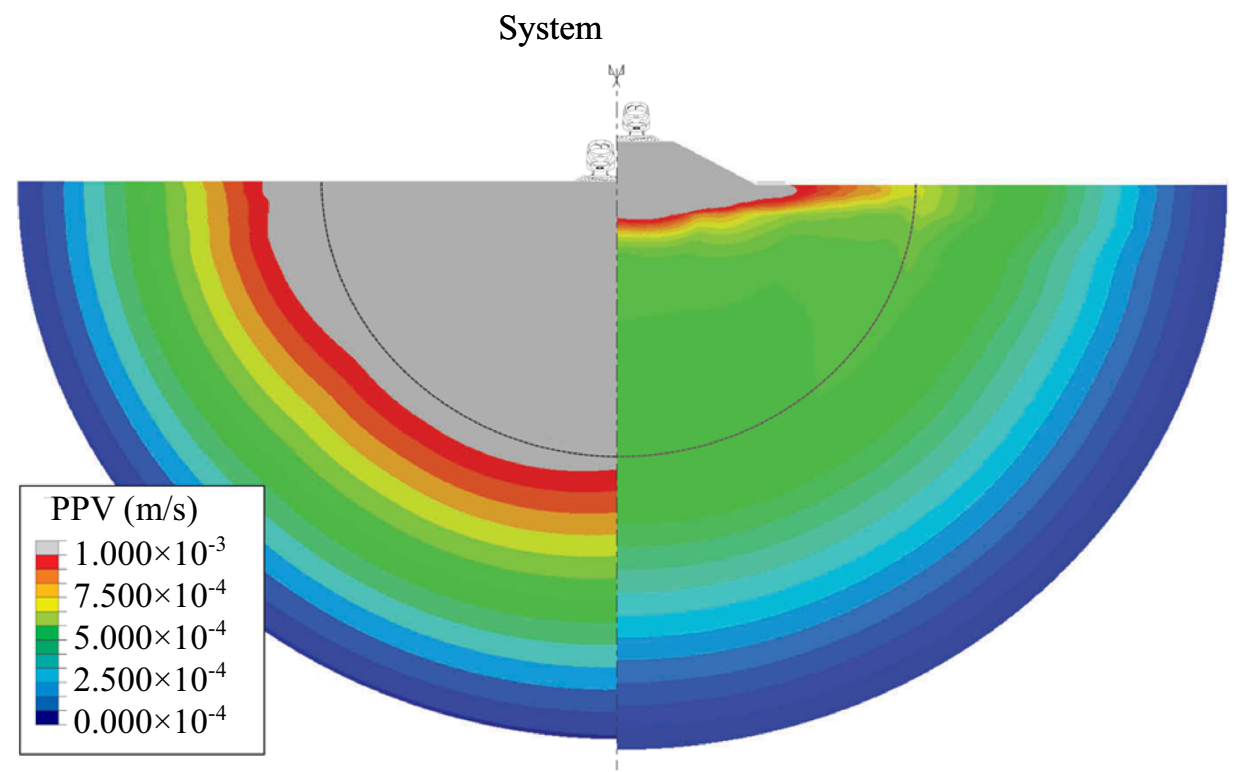

Fig. 15 Numerical visualization (longitudinal planar view) of the ground peak particle velocity generated by the passage of a Thalys high-speed train on track at-grade (left view) and on embankment (right view) [129] 

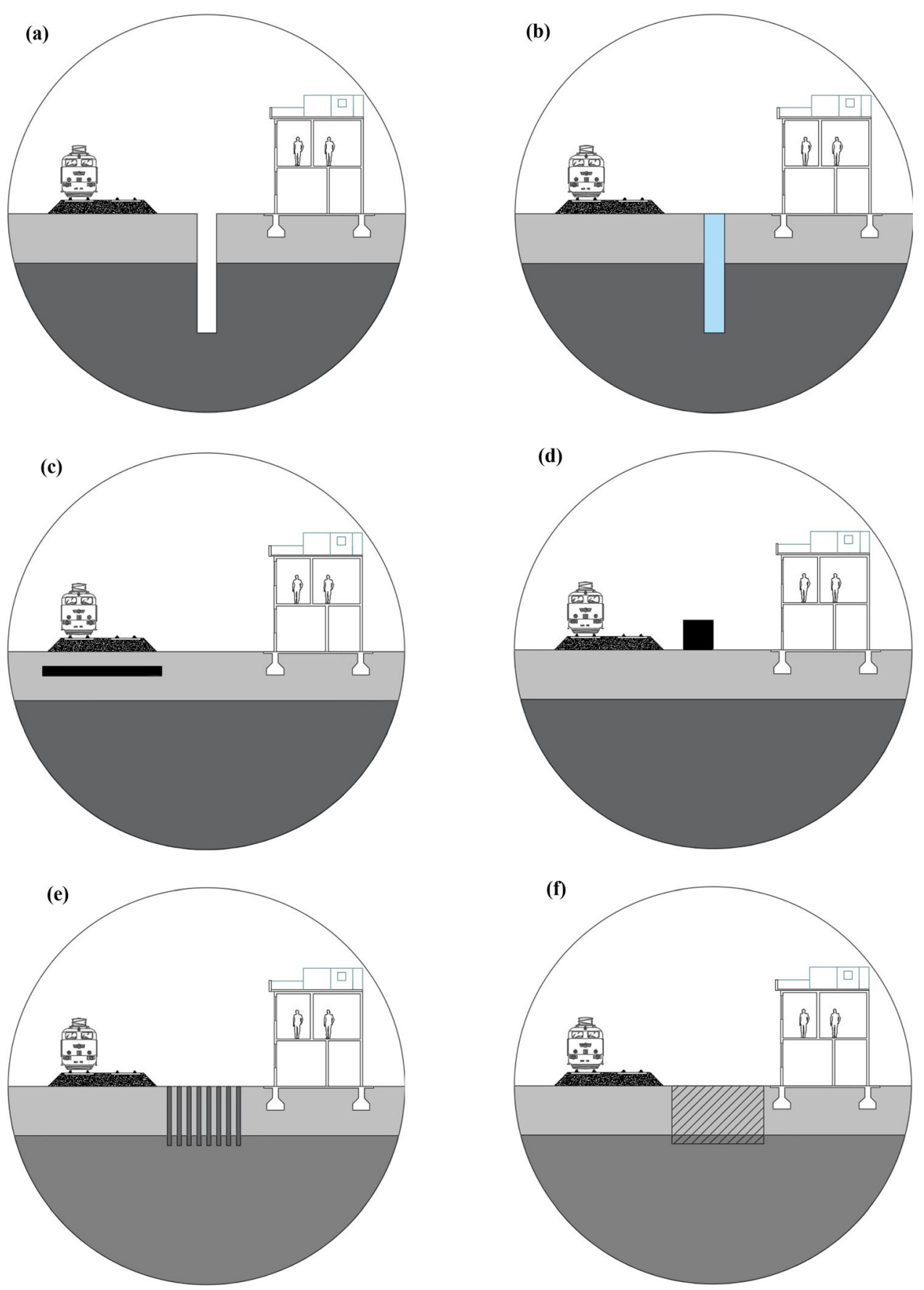

Fig. 16 Illustration of different vibration mitigation measures on the transmission path in 2D: a open trenches; $\mathbf{b}$ soft or stiff barriers; $\mathbf{c}$ impeding blocks barriers; $\mathbf{d}$ heavy mass barriers; e pile barriers; $\mathbf{f}$ soil stiffening barriers

the wavefront hits all the inclusions at the same time not allowing the sonic crystal effect to be triggered.

In addition to these, other mitigation measures can be inserted in this section, even if some differences are present. The wave impeding blocks (represented in Fig. 16c) are stiff inclusions placed under the railway track horizontally to modify the wave propagation in the soil $[140,141]$.
Finally, heavy mass (see Fig. 16d) have been proposed to reduce ground-borne vibration coming from the railway traffic. By placing a gabion wall composed of stone or concrete on the ground surface next to the track [142], it is possible to have an attenuation of vibration at frequencies above the resonance frequency of the masses on the ground stiffness [143]. Two-dimensional (2D) calculations indicate insertion loss values up to $10 \mathrm{~dB}$ in a frequency range 
from about $20 \%$ below to about $20 \%$ above the natural frequency [144].

\subsubsection{Soil stiffening}

It is also possible to mitigate the ground vibration intervening in the geotechnical proprieties of the soil around the track, either under the track, by stiffening the sub-grade as depicted in Fig. 16f, in order to improve the bearing capacity and therefore reducing ground vibration [145] (but they are not practical since need interruption of railway operation), or between the source and the receiver by performing various methods of soil stiffening (lime modification, lime injection and jet grouting) it is possible to get improve the soil absorption capacity. Research has shown that reducing the coherence of the soil allows reducing vibration by $14 \mathrm{~dB}$ within the frequency of $4-32 \mathrm{~Hz}$ [16].

In addition to all the mitigation measures that can be applied within the transmission path, one should consider the exact soil characteristics since these have a direct relationship with the propagation of the waves. Degrande investigated through in situ measurements and numerical calculations [146], the relationship among the soil characteristic, waves velocity and their frequencies at a different distance.

\subsection{Improvement at the receiver}

The last element part of the railway environment affected by the effects is the receiver, generally buildings where vibration is perceived. Generally, in construction, mitigation measures are applied for vibration waves much more severe than the ones coming from the rail, such as antiseismic devices [147]. In railway, precedence is given to the mitigation measures at source and in the transmission path (presented previously), in view of the fact that these are more effective and economical [16].

However, the relevance and advantages of applying the measures before reaching the receiver. Sometimes, for example with a new building near an existing railway and/ or insensitive spaces (such as theatres, concert halls, historical buildings), it is necessary to introduce base isolation within the building itself [148].

Table 3 Vibration reduction at source-rail vehicles

\begin{tabular}{lll}
\hline Mitigation measure & $\begin{array}{l}\text { Vibration } \\
\text { reduction }(\mathrm{dB})\end{array}$ & References \\
\hline Improving wheel roundness & $2-10$ & {$[7,149]$} \\
Reduction of the unsprung mass & $2-10$ & {$[7,149]$} \\
Reduction of speed & $3-6$ & {$[61,62,106]$} \\
Resilient wheels & $3-4$ & {$[27,61,102]$} \\
\hline
\end{tabular}

There are different factors that influence levels of ground-borne vibration and noise at the receiver level. Such as the foundation type and the building construction, where generally applies rule-of-thumb i.e., the more massive the foundation (or building), the lower the levels of ground-borne vibration; and the amount of acoustical absorption in the receiver room that affects the levels of the ground-borne noise [61].

The measures that can be applied are different. At the foundation level, it is possible for example to introduce a vertical elastic layer around the foundation in order to create protection around it and protect it from vibration waves, a reduction between 2 and $6 \mathrm{~dB}$ for ground-borne noise can be obtained. At the same level for new sensitive buildings, a resilient bearing, which generally consists of steel coil springs or elastomeric bearings, can be introduced in the foundation (generally for underground lines), in this case, the reduction can reach $20-26 \mathrm{~dB}$ both for vibration and ground-borne noise. Whereas at the construction level for one-storey buildings. it is possible to stiff the ground floor by using piles (reduction up to $2 \mathrm{~dB}$ ), or in addition in case of wooden floors, the stiffness of the floor can be improved by inserting additional beams to support the floor (reduction up to $20 \mathrm{~dB}$ ) [7].

The improvements mentioned above have generally a considerable interaction with surrounding existing construction, and their cost in some cases increases exponentially especially when the proposal is to apply them to the existing building. This is an additional reason that makes them the last choice in the available mitigation techniques.

\section{Summary}

In modern times, the vibrations to which buildings and residents are exposed are of different types, the majority of those are generally accepted by public opinion. However, vibrations such as the one generated by rail traffic are often a subject of concern among the residents (although it is not a new event); furthermore, the expected growth of the railway grid in the next future due to its sustainability requires to take measures in order to minimize this drawback. Due to the importance of this issue in this paper, the railway vibration and the way to tackle it have been introduced and discussed in detail. Considering the ongoing research in this field certain conclusion and comments can be made:

1. Rail traffic vibration generated at the wheel-rail contact has a different threshold of acceptance from country to country. Because of this different standards are available to regulate it, both international (e.g., ISO 2631, ISO 4866 and BS EN 12299) and national (e.g., 
Table 4 Vibration reduction at source-track

\begin{tabular}{lll}
\hline Mitigation measure & Vibration reduction $(\mathrm{dB})$ & References \\
\hline Rail enhancements & $8-19$ & {$[106-108]$} \\
Fasteners enhancements & $5-20$ & {$[61,109,111]$} \\
Sleepers and ballast enhancements & $3-20$ & {$[7,61,116]$} \\
Other track technologies & $5-40$ & {$[16,107,117,123]$}
\end{tabular}

Table 5 Vibration reduction at the transmission path

\begin{tabular}{lll}
\hline Mitigation measure & $\begin{array}{l}\text { Vibration } \\
\text { reduction }\end{array}$ & References \\
\hline $\begin{array}{l}\text { Increasing the } \\
\text { distance }\end{array}$ & Variable & {$[61,124,125]$} \\
$\begin{array}{l}\text { Embankment } \\
\text { Protection barriers }\end{array}$ & $5 \mathrm{~dB}$ & {$[106,128]$} \\
Soil stiffening & $14 \mathrm{~dB}$ & {$[7,134,135,137,138]$} \\
\hline
\end{tabular}

BS 6841, DIN 4150, SN 640 312a and NS 8167). Those comprehend underground and surface trains both for freight and passenger transport.

2. Evaluation of the vibration waves is assessed according to the type of the line, the conditions of service and the characteristics of the transmission path. Deformation in the wheel-rail and the velocity are the main contributors in the vibration waves frequencies, those can contribute from $4 \mathrm{~Hz}$ in case of wheel unevenness at low velocity $(40 \mathrm{~km} / \mathrm{h})$ up to $2000 \mathrm{~Hz}$ at high velocity $(160 \mathrm{~km} / \mathrm{h})$ as depicted in Table 1 . The principal waves generated at the wheel-rail contact and propagate through the soil are the compression (velocity range $800-1500 \mathrm{~m} / \mathrm{s}$ ), shear (velocity range $200-500 \mathrm{~m} / \mathrm{s}$ ) and Rayleigh waves (velocity range typically $10 \%$ lower than S-waves).

3. The ground-borne effects creates generally two negative consequences, an annoyance to humans and to some extent damage to buildings and equipment. It becomes therefore crucial to mitigate this effect in order to minimize these effects. Mitigation measures that are the central subject of this paper might be applied in a different part of the rail environment, i.e., vehicle, rail track, transmission path and at the receivers:

(a) Improvement in the vehicle. The fact that the source of ground-borne vibration and noise is coming from the wheel-rail contact makes different techniques available within the vehicle, especially at the level of the wheels (see Table 3).

(b) Improvement in the track. The track being the other the track the other part of the generation of the vibration, its components (e.g., rail, rail pad, sleepers and ballast) play a fundamental role in the generation of vibration waves. Therefore, mitigation measure inside the track can produce relevant attentions (see Table 4). In addition, a mitigation measure in the track is one for all the passing trains.

(c) Improvement in the path. Once wave vibrations are generated in the source area, they propagate through the soil outward from the rail. Their velocity depends on the intrinsic characteristics of the soil where they propagate. For this reason, by playing and developing the latter it is possible to reduce the effects (see Table 5). These measures for their easy fit to exiting lines and their costs have been the most used in the past decades.

(d) Improvement at the receiver. It is possible also to reduce the vibration effects exactly in the element subjected to the motion (i.e., building). Generally, the measures are applied in the foundations that are the point where the excitation is transferred from the soil to the construction. Employment of mitigation measures at the receiver is commonly used to prevent seismic events, however, interesting use can be done also for railway effects reaching mitigation up to $26 \mathrm{~dB}$.

4. Different efficient approaches are available, as presented, to mitigate the vibration coming from rail passage, therefore it is necessary to study the most convenient in terms of the environmental and financial cost.

\section{Prospective research direction}

The mitigation methods available in the literature are of different types and are applicable to the different levels of the railway environment as emerged through this paper. Work such as this, which draw a comparison of the available mitigation systems, provides a benchmark reference to the railway industry and beyond when searching to find the best solution for a project.

The selection of a measure over another is often dictated by the applicability of the measure to the project, by its impact in the ecosystem and in terms of investment. In this 
direction, a promising technology that needs to look at in the next future is the one of meta-material used in the different parts of the railway system to implement the existing measures, as presented earlier in this manuscript in the case of phonetic crystal barriers [71]. Meta-materials are natural or artificial materials or structures which exhibit extraordinary properties (gained thanks to the structure and not material composition [150]) for inhibiting or conditioning wave propagation in all spatial directions [151].

Acknowledgements This work was financially supported by the European Union's Horizon 2020 research and innovation programme under the Marie Skłodowska-Curie grant agreement No INSPIRE813424. The authors would like also to thank Professor Christos Vrettos, from Technical University of Kaiserslautern, for the discussions and for his valuable comments and suggestions.

Open Access This article is licensed under a Creative Commons Attribution 4.0 International License, which permits use, sharing, adaptation, distribution and reproduction in any medium or format, as long as you give appropriate credit to the original author(s) and the source, provide a link to the Creative Commons licence, and indicate if changes were made. The images or other third party material in this article are included in the article's Creative Commons licence, unless indicated otherwise in a credit line to the material. If material is not included in the article's Creative Commons licence and your intended use is not permitted by statutory regulation or exceeds the permitted use, you will need to obtain permission directly from the copyright holder. To view a copy of this licence, visit http://creativecommons. org/licenses/by/4.0/.

\section{References}

1. Vogiatzis KE, Kouroussis G (2017) Environmental GroundBorne Noise and Vibration from Urban Light Rail Transportation During Construction and Operation. Curr Pollut Rep 3:162-173

2. Yang YB, Hsu LC (2006) A Review of Researches on GroundBorne Vibrations Due to Moving Trains via Underground Tunnels. Advances in Structural Engineering 9(3):377-392

3. European Union (2020) An official website of the European Union. https://ec.europa.eu. Accessed 4 Sept 2020

4. Li L, Zhang X (2020) Integrated optimization of railway freight operation planning and pricing based on carbon emission reduction policies. Journal of Cleaner Production 263: 12316

5. Jones R (2010) Applied acoustics, Elsevier Ltd 71(9): 885-887. ISSN 0003-682X (2010)

6. Knall V (1996) Railway noise and vibration: effects and criteria. J Sound and Vib 193(1):9-20

7. Satis PV (2017) Railway induced vibration-State of the art Report, UIC International Union of Railways

8. International Organisation for Standardization. ISO 14837:2005: mechanical vibration-ground borne noise and vibration arising from rail systems-Part 1: general guidance

9. Stüber C (1975) Air and structure-borne noise of railways. J Sound and Vib 43(2):281-289

10. De Vos PH (1996) Railway noise: the physics of airbrone sound generation and propagation. J Sound and Vib 193(1):77-82
11. Zhang J, Xiao X, Sheng X et al (2019) Sound source localisation for a high-speed train and its transfer path to interior noise. Chin J Mech Eng 32(1):59

12. Bass HE, Sutherland LC, Zuckerwar AJ, Blackstock DT, Hester DM (1995) Atmospheric absorption of sound: Further developments. J Acoust Soc Am 97(1):680-683

13. ANSI Standard S1-26:1995, Calculation of the absorption of sound by the atmosphere (ISO 9613-1:1996)

14. Casini D, Cellai G, Fogola J, Scamoni F, Secchi S (2016) Correlation between facade sound insulation and urban noise: A contribution to the acoustic classification of existing buildings. Build Acoust 23(3-4):145-158

15. Maclachlan L, Ögren M, Kempen E, Alkhateeb LH, Persson W (2018) Annoyance in Response to Vibrations from Railways. Int J Environ Res Public Health 15(9): 1887

16. Hemsworth B (2000) Reducing ground-borne vibrations: stateof-the-art study. J Sound and Vib 231(3): 703-709

17. Gidlöf-Gunnarsson A, Ögren M, Jerson T, Öhrström E (2012) Railway noise annoyance and the importance of number of trains, ground vibration, and building situational factors. Noise \& Health a Bimonthly Interdisciplinary International Journal 14(59): 190-201

18. Sörensen S, Hammar N (1983) Annoyance reactions due to railway noise. Journal of Sound and Vibration 87(2): 315-319

19. Croy I, Smith MG, Waye KP (2013) Effects of train noise and vibration on human heart rate during sleep: an experimental study. BMJ Open 3:e002655

20. Maclachlan L, Waye KP, Pedersen E (2017) Exploring perception of vibrations from rail: an interview study. Int J Environ Res Public Health 14(11):1302

21. Kouroussis G, Connolly DP, Verlinden O (2014) Railway-induced ground vibrations-a review of vehicle effect. Int J Rail Transp 2(2):69-110

22. Kouroussis G, Vogiatzis KE, Connolly DP (2017) A combined numerical-experimental prediction method for urban railway vibration. Soil Dyn Earthq Eng 97:377-386

23. Ouakka S, Verlinden O, Kouroussis G (2021) Mitigation measures dedicated to railway-induced ground vibration: an analysis of recent advances. In: 27th International Congress on Sound and Vibration, pp. 11-16

24. Smith GM, Ögren M, Morsing JA, Waye KP (2019) Effects of ground-borne noise from railway tunnels on sleep: a polysomnographic study. Build Environ 149:288-296

25. Smith GM, Croy I, Ögren M, Hammar O, Lindberg E, Waye KP (2017) Physiological effects of railway vibration and noise on sleep. J Acoust Soc Am 141(5):3262-3269

26. Öhrström E (1997) Effects of exposure to railway noise-a comparison between areas with and without vibration. J Sound and Vib 205(4): 555-560

27. Kouroussis G, Zhu S, Olivier B, Ainalis D, Zhai W (2019) Urban railway ground vibrations induced by localized defects: using dynamic vibration absorbers as a mitigation solution. J Zhejiang Uni-Sci A 20(2): 83-97

28. Kouroussis G, Vogiatzis KE, Kassomenos P (2019) The effect of transportation vibration on the urban acoustic environment. Sci Total Environ 650(2):2640

29. Ulgen D, Ertugrul OL, Ozkan MY (2016) Measurement of ground borne vibrations for foundation design and vibration isolation of a high-precision instrument. Measurement 385396:93

30. Xia H, Zhang N, Cao YM (2005) Experimental study of traininduced vibrations of environments and buildings. J Sound and Vib 280:1017-1029

31. Zhang X, Zhou S, He C, Di H, Si J (2020) Experimental investigation on train-induced vibration of the ground railway 
embankment and under-crossing subway tunnels. Transport Geotech 26:100422

32. Kouroussis G, Verlinden O, Conti C (2011) Free field vibrations caused by high-speed lines: Measurement and time domain simulation. Soil Dyn Earthq Eng 31(4):692-707

33. Kouroussis G, Verlinden O (2014) Numerical prediction of ground vibrations generated by domestic trains in Brussels. In: Proceedings of the 21st international congress on sound and vibration, Beijing

34. Kouroussis G, Vogiatzis KE, Connolly DP (2018) Assessment of railway ground vibration in urban area using in-situ transfer mobilities and simulated vehicle-track interaction. Int $\mathbf{J}$ Rail Transportation 6(2):113-130

35. Connolly DP, Galvín P, Olivier B, Romero A, Kouroussis G (2019) A 2.5D time-frequency domain model for railway induced soil-building vibration due to railway defects. Soil Dynamics and Earthquake Engineering 120:332-344

36. Alves Costa P, Calçada R, Couto Marques J, Cardoso A (2010) A 2.5D finite element model for simulation of unbounded domains under dynamic loading. In: Numerical Methods in Geotechnical Engineering-Proceedings of the 7th European Conference on Numerical Methods in Geotechnical Engineering, pp. 397-404

37. Bacciocchi M, Tarantino A (2019) Natural frequency analysis of functionally graded orthotropic cross-ply plates based on the finite element method. Math Comput Appl 24:52

38. Ouakka S, Fantuzzi N (2019) Trustworthiness in modeling reinforced and reinforced T-joints with finite elements. Math Comput Appl 24:27

39. Sheng X, Jones CJC, Petyt M (1999) Ground vibration generated by a harmonic load acting on a railway track. J Sound Vib 225:3-28

40. Kaynia AM, Madshus C, Zackrisson P (2000) Ground vibration from high-speed trains: prediction and countermeasure. J Geotech Geoenviron Eng 126:531-537

41. Madshus C, Kaynia AM (2000) High-speed railway lines on soft ground: dynamic behaviour at critical train speed. J Sound Vib 231:689-701

42. Vrettos C (2017) Bodendynamik. In: Witt KJ (ed) GrundbauTaschenbuch. https://doi.org/10.1002/9783433607275.ch9

43. Hall L (2003) Simulations and analyses of train-induced ground vibrations in finite element models. Soil Dyn Earthq Eng 23:403-413

44. El Kacimi A, Woodward PK, Laghrouche O, Medero G (2013) Time domain 3D finite element modelling of train-induced vibration at high speed. Comput Struct 118:66-73

45. Shih JY, Thompson D, Zervos A (2014) Assessment of trackground coupled vibration induced by high-speed trains. In: 21 st international congress on sound and vibration, pp. 13-17

46. Kouroussis G, Verlinden O, Conti C (2012) A two-step time simulation of ground vibrations induced by the railway traffic. J Mech Eng Sci 226(2): 545-72

47. Kouroussis G, Van Parys L, Conti C, Verlinden O (2014) Using three-dimensional finite element analysis in time domain to model railway-induced ground vibrations. Adv Eng Softw 70:63-76

48. Lombaert G, Degrande G, François S, Thompson DJ (2015) Ground-borne vibration due to railway traffic: a review of excitation mechanisms, prediction methods and mitigation measures, noise and vibration mitigation for rail transportation system. Springer, Berlin Heidelberg pp. 253-287

49. Baziar MH, Kazemi M, Shahnazari M (2019) Mitigation of ground vibrations induced by high speed railways using double geofoam barriers: centrifuge modeling. Geotext Geomembr 47(6):712-728
50. International Organisation for Standardization. ISO 2631-1:1997: mechanical vibration and shock-evaluation of human exposure to whole-body vibration-part 1: general requirements

51. International Organisation for Standardization. ISO 2631-2:2003: Mechanical vibration and shock-evaluation of human exposure to whole-body vibration-part 2: vibration in buildings $(1 \mathrm{~Hz}$ to $80 \mathrm{~Hz}$ )

52. BS EN 12299 (2009) Railway applications-ride comfort for passenger-measurement and evaluation

53. International Organization for Standardization (2010) ISO 4866: mechanical vibration and shock- vibration of fixed structuresguidelines for the measurement of vibrations and evaluation of their effects on structures

54. British Standard (1987) BS 6841: measurement and evaluation of human exposure to whole-body mechanical vibration and repeated shock

55. British Standard (2008) BS6472-1: Measurement and evaluation of human exposure to whole-body mechanical vibration and repeated shock

56. Deutsches Institut für Normung (1999) DIN4150-2: structural vibrations-part 2: human exposure to vibration in buildings

57. Deutsches Institut für Normung (1999) DIN 4150-3: structural vibrations-part 3: effects of vibration on structures

58. Association Suisse d eNormalisation (1992) SN-640312a: Les ébranlements-effet des ébranlements sur les constructions

59. Standards Norway (2005) NS 8176: vibration and shockmeasurement of vibration in buildings from landbased transport and guidance to evaluation of effects on human beings

60. Hanson CE, Ross JC, Towers DA (2012) High-speed ground transportation noise and vibration impact assessment. Federal Rail road Adm, DOT/FRA/ORD-12/15

61. Hanson CE, Towers DA, Meister LD (2006) Transit noise and vibration impact assessment. Federal Transit Adm, FTA-VA-901003-06

62. Thompson DJ, Kouroussis G, Ntotsios E (2019) Modelling, simulation and evaluation of ground vibration caused by rail vehicles. Veh Syst Dyn 57(7): 936-983

63. Lombaert G, Degrande G (2009) Ground-borne vibration due to static and dynamic axle loads of InterCity and high-speed trains. J Sound Vib 319:1036-1066

64. Connolly DP, Kourousis G, Laghrouche O, Ho CL, Frode MC (2014) Benchmarking railway vibrations-track, vehicle, ground and building effects. Constr Build Mater 92:64-81

65. Kurhan D (2016) Determination of load for quasi-static calculations of railway track stress-strain state. Acta Technica Jaurinensis 9(1):83-96

66. Connolly DP (2013) Ground borne vibrations from high-speed trains. Dissertation, University of Edinburgh, pp 83-96

67. Yin X, Xu H, Mi B, Hao X, Wang P, Zhang K (2020) Joint inversion of Rayleigh and Love wave dispersion curves for improving the accuracy of near-surface S-wave velocities. J Appl Geophys 176:103939

68. Giannoula A, Cobbold RSC, Bezerianos A (2013) Estimating the local viscoelastic properties from dispersive shear waves using time-frequency ridge analysis. Ultrasonics 53(2): 534-544

69. Rahman, M., Michelitsch, T. (2006) A note on the formula for the Rayleigh wave speed. Wave Motion 34(3): 272-276

70. Malischewsky P (2005) Comparison of approximated solutions for the phase velocity of Rayleigh waves (Comment on 'Characterization of surface damage via surface acoustic waves'). Nanotechnology 16:995-996

71. Albino C, Godinho L, Amado-Mendes P, Alves-Costa P, Diad da-Costa D, Soares D (2019) 3D FEM analysis of the effect of buried phononic crystal barriers on vibration mitigation. Eng Struct 196:109340 
72. Hiller DM, Crabb GI (2000) Groundborne vibration caused by mechanised construction work. Prepared for quality servicescivil engineering, Highways agency

73. British Standards. BS 7385-2:1993: Evaluation and measurement for vibration in buildings. Guide to damage levels from ground borne vibration

74. Ewert MHK, Ridker PM, Rifai N et al (2004) Effect of sleep loss on C-reactive protein, an inflammatory marker of cardiovascular risk. J Am Coll Cardiol 43: 678-693

75. Babisch W (2002) The noise/stress concept, risk assessment and research needs. Noise Health 4(16):1-11

76. Carter NL, Ingham P, Tran K et al. (1994) A field-study of the effects of traffic noise on heart-rate and cardiac-arrhythmia during Sleep. J Sound Vib 169: 211-227

77. Corbridge C, Griffin MJ (1991) Effects of vertical vibration on passenger activities: writing and drinking. Ergonomics 34(10):1313-1331

78. Sundstrom J, Khan S (2008) Influence of stationary lateral vibrations on train passengers' difficulty to read and write. Appl Ergon 39(6):710-8

79. Suzuki H (1998) Research trends on riding comfort evaluation in Japan. Proc Inst Mech Eng Part F: J Rail Rapid Transit 212(12):61-72

80. Piersol AG, Paez TL (2009) Harris' shock and vibration handbook (5th ed.). McGraw-Hill handbooks, isbn:9780071633437

81. Vogiatzis K, Kouroussis G (2015) Prediction and efficient control of vibration mitigation using floating slabs: Practical application at Athens metro lines 2 and 3. Int J Rail Transp 3(4):215-232

82. Zhu S, Wang J, Cai C, Wang K, Zhai W, Yang J, Yan H (2017) Development of a vibration attenuation track at low frequencies for urban rail transit. Comput-Aided Civ Infrastruct Eng 32(9):713-726

83. Carels P, Ophalffens K, Vogiatzis K (2012) Noise and vibration evaluation of a floating slab in direct fixation turnouts in haidari $\&$ anthoupoli extentions of Athens metro lines 2 and 3. Ing Ferrov 67(6):533-553

84. Eugene IR (2003) Passive vibration isolation. ASME Press, New York

85. Lombaert G, Degrande G, Vanhauwere B, Vandeborght B, François $S$ (2006) The control of ground-borne vibrations from railway traffic by means of continuous floating slabs. J Sound Vib 297(3-5):946-961

86. Castanheira-Pinto A, Alves-Costa P, Godinho L, Amado-Mendes $\mathrm{P}$ (2018) On the application of continuous buried periodic inclusions on the filtering of traffic vibrations: A numerical study. Soil Dyn Earthq Eng 113:391-405

87. Li X, Nielsen JCO, Torstensson PT (2019) Simulation of wheelrail impact load and sleeper-ballast contact pressure in railway crossings using a Green's function approach. J Sound Vib 463:114949

88. Zhou W, Abdulhakeem S, Fang C, Han T, Li G, Wu Y, Faisal Y (2020) A new wayside method for measuring and evaluating wheel-rail contact forces and positions. Measurement $166: 108244$

89. Xu J, Wang K, Liang X, Gao Y, Liu Z, Chen R, Wang P, Xu F, Wei K (2020) Influence of viscoelastic mechanical properties of rail pads on wheel and corrugated rail rolling contact at high speeds. Tribol Int 151:106523

90. Wilson GP, Saurenman HJ, Nelson JT (1983) Control of ground-borne noise and vibration. J Sound Vib 87(2):339-350

91. Nelson JT (1996) Recent developments in ground-borne noise and vibration control. J Sound Vib 193(1):367-376

92. Alves Costa P, Calçada R, Silva Cardoso A (2012) Influence of train dynamic modelling strategy on the prediction of track- ground vibrations induced by railway traffic. J Rail Rapid Transit 226(4):434-450

93. Alves Costa P, Calçada R, Cardoso A (2012) Track-ground vibrations induced by railway traffic: In-situ measurements and validation of a D FEM-BEM model. Soil Dyn Earthq Eng 32:111-128

94. RIVAS Railway Induced Vibration Abatement Solutions Collaborative project (2013)

95. Nielsen J, Johansson A (2000) Out-of-round railway wheels - a literature survey. Proc Inst Mech Eng Part F: J Rail Rapid Transit 214(2):79-91

96. Wu Y, Du X, Zhang HJ, Wen Z, Jin X (2017) Experimental analysis of the mechanism of high-order polygonal wear of wheels of a high-speed train. J Zhejiang Univ-Sci A 18(8):579-592

97. Holm G, Andreasson B, Bengtsson P, Bodare A, Eriksson H (2012) Mitigation of track and ground vibration by high speed trains at Ledsgard, Sweeden. Report 10, Svensk Djupstabilisering

98. Dong K, Connolly DP, Laghrouche O, Woodward PK, Alves Costa P (2019) Non-linear soil behaviour on high speed rail lines. Comput Geotech 112:302-318

99. Connolly DP, Alves Costa P (2020) Geodynamics of very high speed transport systems. Soil Dyn Earthq Eng 130:105982

100. Madshus C, Lacasse S, Kaynia A, Harvik L (2014) Geodynamic challenges in high speed railway projects. Geotech Eng Transport Project pp. 192-215

101. Degrande G, Schevenels M, Chatterjee P, Van de Velde W, Hölscher P, Hopman V, Wang A, Dadkah N (2006) Vibrations due to a test train at variable speeds in a deep bored tunnel embedded in London clay. J Sound Vib 293(3-5):626-644

102. Kouroussis G, Verlinden O, Conti C (2012) Efficiency of resilient wheels on the alleviation of railway ground vibrations. Proc Inst Mech Eng Part F: J Rail Rapid Transit 226(4):381-396

103. Remennikov A, Kaewunruen S (2005) Investigation of vibration characteristics of prestressed concrete sleepers in free-free and in-situ conditions. Australian Structural Engineering Conference 2005 (ASEC 2005), Copyright Institution of Engineers Australia, Newcastle, Australia, pp 11-14

104. Pita A, Teixeira PF, Robuste F (2004) High speed and track deterioration: the role of vertical stiffness of the track. Proc Inst Mech Eng Part F: J Rail Rapid Transit 218(1):31-40

105. Dahlberg T (2010) Railway track stiffness variations - consequences and countermeasures. Int J Civ Eng 8(1):1-12

106. Lakušić S, Ahac M (2012) Rail traffic noise and vibration mitigation measures in urban areas. Tehnicki Vjesnik 19(2):427-435

107. Eszter L (2004) Mitigation of railway noise and vibration concentrating on the reducing at source methods. Intersections/Intersectii 1(2):3-11

108. Benton D (2006) Engineering aspects of rail damper design and installation. RAIL-NOISE 2006, Pisa

109. Bewes OG, Jakielaszek LJ, Richardson ML (2007) An assessment of the effectiveness of replacing slab track to control ground-borne noise and vibration in buildings above an existing railway tunnel. In: Proceedings of the 9th International Workshop on Railway Noise, Munich, Germany

110. D2S International (2020) Engineers specialised in acoustics, noise, vibration and dynamics. http://www.d2sint.com. Accessed 18 May 2020

111. Verdict Media Limited (2020) Railway Technology website. https://www.railway-technology.com/. Accessed 16 July 2020

112. Pandrol (2020) Pandrol website. https://www.pandrol.com. Accessed 21 June 2020 
113. Ferro E, Harkness J, Le Pen L (2020) The influence of sleeper material characteristics on railway track behaviour: concrete vs composite sleeper. Transp Geotech 23:100348

114. Mateus EP, Gomes da Silva MDR, Ribeiro AB, Marriott PJ (2008) Qualitative mass spectrometric analysis of the volatile fraction of creosote-treated railway wood sleepers by using comprehensive two-dimensional gas chromatography. J Chromatogr A 1178(1-2):215-222

115. Bongini E, Müller R, Garburg R, Pieringer A (2012) Design guide and technology assessment of the track mitigation measures. RIVAS project, SCP0-GA-2010-265754, Report to the EC (Deliverable D3.13)

116. Sol-Sánchez M, Moreno-Navarro F, Rubio-Gámez MC (2015) The use of elastic elements in railway tracks: a state of the art review. Constr Build Mater 75:293-305

117. Wheel/Rail Noise (1997) Transportation research board, Report 23, Washington DC

118. Grootenhuis P (1977) Floating track slab isolation for railways. J Sound Vib 51(3):443-448

119. Mouzakis C, Vogiatzis K, Zafiropoulou V (2019) Assessing subway network ground borne noise and vibration using transfer function from tunnel wall to soil surface measured by muck train operation. Science of the Total Environment 650:2888-2896

120. Liu L, Shao W (2011) Design and dynamic response analysis of rail with constrained damped dynamic vibration absorber. Proced Eng 15:4983-4987

121. Vincent N, Bouvet P, Thompson DJ, Gautier PE (1996) Theoretical optimization of track components to reduce rolling noise. J Sound Vib 193(1):161-171

122. Zhu SY, Yang JZ, Cai CB et al. (2017) Application of dynamic vibration absorbers in designing a vibration isolation track at low-frequency domain. Proc Inst Mech Eng Part F: J Rail Rapid Transit 231(5):546-557

123. Noori B, Arcos R, Clot A, Romeu J (2019) Control of groundborne underground railway-induced vibration from double-deck tunnel infrastructures by means of dynamic vibration absorbers. J Sound Vib 461:114914

124. Assessing vibration: a technical guideline (2006) Environmental noise management. Department of Environment and Conservation NSW

125. DUAP, Assessment of noise, vibration and blasting impacts (1997) EIS manual. Department of Urban Affairs and Planning, Sydney

126. Connolly D, Giannopoulos A, Forde M (2013) Numerical modelling of ground borne vibrations from high speed rail lines on embankments. Soil Dyn Earthq Eng 46:13-19

127. Ju SH, Liao JR, Ye YL (2010) Behavior of ground vibrations induced by trains moving on embankments with rail roughness. Soil Dyn Earthq Eng 30:1237-1249

128. Shanna \& Wilson, Inc. (1971) Embankment support for a railroad track: construction report. Tracks \& Structures, FRA-RT$72-07$

129. Olivier B, Connolly DP, Costa PA, Kouroussis G (2016) The effect of embankment on high speed rail ground vibrations. Int $\mathbf{J}$ Rail Transp 4(4):229-246

130. Lyratzakis A, Tsompanakis Y, Psarropoulos PN (2020) Efficient mitigation of high-speed trains induced vi-brations of railway embankments using expanded polystyrene blocks. Transp Geotech 22:100312

131. Lyratzakis A, Tsompanakis Y, Psarropoulos PN (2020) Mitigation of high-speed trains vibrations by expanded polystyrene blocks in railway embankments. J Zhejiang Univ-Sci A: Appl Phys \& Eng 22:6-20

132. Celebi E, Kinrtel O (2013) Non-linear 2-D FE modelling for prediction of screening performance of thin-walled trench barriers in mitigation of train-induced ground vibration. Constr Build Mater 42:122-131

133. Woods R (1968) Screening of surface waves in soils. J Soil Mech Found Div Proc ASCE 94(SM4):951-79

134. Thompson DJ, Jiang J, Toward MGR, Hussein MFM, Ntotsios E, Dijckman A, Coulier P, Lombaert G, Degrande G (2016) Reducing railway-induced ground-borne vibration by using open trenches and soft-filled barriers. Soil Dyn Earthq Eng 88:45-59

135. Massarsch K (2005) Vibration isolation using gas-lled cushions. In: Proceedings of the GeoFrontiers 2005 Congress. American Society of Civil Engineers, Austin

136. Hassoun M, Ulgen D, Toygar O, Durmaz S (2019) Numerical study on reducing the ground borne vibrations using open trench and rubber-chips filled trench wave barriers. In: 1st Mediterranean young geotechnical engineers conference, Mulga, Turkey

137. Francois S, Schevenels M, Thyssen B, Borgions J, Degrande G (2012) Design and eciency of a composite vibration isolating screen in soil. Soil Dyn Earthq Eng 39:113-127

138. Coulier P, Dijckmans A, Jiang J et al (2015) Stiff wave barriers for the mitigation of railway induced vibrations. In: Nielsen J, et al. (eds) Noise and Vibration Mitigation for Rail Transportation Systems. Notes on Numerical Fluid Mechanics and Multidisciplinary Design, vol 126. Springer, pp. 539-546

139. Kattis SE, Polyzos D, Beskos DE (1999) vibration isolation by a row of piles using a 3-d frequency domain BEM. Int J Numer Meth Engng 46:713-728

140. Peplow A, Jones C, Petyt M (1999) Surface vibration propagation over a layered halfspace with an inclusion. Appl Acoustics 56:283-296

141. Takemiya H, Fujiwara A (1994) Wave propagation/impediment in a stratum and wave impeding block (WIB) measured for SSI response reduction. Soil Dyn Earthq Eng 13:49-61

142. Krylov V (2005) Scattering of rayleigh waves by heavy masses as method of protection against trac-induced ground vibrations. In: Takemiya $\mathrm{H}$ (ed) Environmental vibrations prediction, monitoring, mitigation and evaluation. Taylor and Francis Group, London, pp. 393-398

143. Dijckmans A, Coulier P, Jiang J et al (2015) Mitigation of railway induced ground vibration by heavy masses next to the track. Soil Dyn Earthq Eng 75:158-170

144. Krylov V (2007) Control of trafc-induced ground vibrations by placing heavy masses on the ground surface. J Low Freq Noise Vib Active Control 26(4):311-20

145. Adam D, Vogel A, Zimmermann A (2007) Ground improvement techniques beneath existing rail tracks. Ground Improv 11(4):229-235

146. Degrande G (2001) Free-field vibrations during the passage of a high-speed train: experimental results and numerical predictions. In: Noise Vib High-speed Trains, Thomas Telford Publishing, London, pp. 285-314. https://www.icevirtuallibrary. com/doi/abs/10.1680/navfht.29637.0010

147. Castellano MG, Infanti S (2020) Recent applications of Italian anti-seismic devices. In: Earthquake Resistant Engineering Structures VII, Bilbao, Spain

148. Talbot JP (2016) Base-isolated buildings: towards performancebased design. Proc Inst Civil Eng Struct Build 169(8):574-582

149. Nielsen J, Mirza A, Cervello S, Huber P, Müller R, Nelain B, Ruest P (2015) Reducing train-induced ground-borne vibration by vehicle design and maintenance. Int J Rail Transp 3(1):17-39

150. Selimis A, Farsari M (2017) 3.8 laser-based 3D printing and surface texturing. Compr Mater Finish 3:111-136

151. Inspire (2020) Marie Skłodowska-Curie INSPIRE project website. https://itn-inspire.eu. Accessed 18 May 2020 